\title{
Model Uncertainty, Financial Markets Integration and the Home Bias Puzzle
}

\author{
Lieven Baele * $\quad$ Crina Pungulescu ${ }^{\dagger} \quad$ Jenke Ter Horst ${ }^{\ddagger}$
}

June 26, 2006

\begin{abstract}
This paper investigates to what extent ongoing integration has eroded the equity home bias. To measure home bias, we compare observed foreign asset holdings of a set of 25 developed markets with optimal weights obtained from 5 benchmark models. Under the assumptions of the classical model in home bias studies, the International CAPM (I-CAPM), optimal portfolio weights are given by the relative world market capitalization shares. Four alternative models that allow for various degrees of mistrust in the I-CAPM and involve returns data in computing optimal portfolio weights, generally indicate a substantially lower yet still positive home bias. We observe a reduction in the home bias for many countries at the end of the 1990s and link the sharp decrease in the equity home bias to time-varying globalization and regional integration.
\end{abstract}

JEL classification: F36, G11, G15

Keywords: Home Bias, Market Integration, Euro, Model Uncertainty

*Tilburg University, Department of Finance, CentER for Economic Research and Netspar, P.O. Box 90153, 5000 LE Tilburg, The Netherlands, email: lieven.baele@uvt.nl, phone: +31 13466 3257, fax: +31 134662875.

${ }^{\dagger}$ Corresponding author. Department of Finance and CentER for Economic Research, Tilburg University, P.O. Box 90153, 5000 LE Tilburg, The Netherlands, email: c.pungulescu@uvt.nl, phone: +31 13466 2020, fax: +31 134662875 .

$\ddagger$ Tilburg University, Department of Finance, CentER for Economic Research and Netspar, P.O. Box 90153, 5000 LE Tilburg, The Netherlands, email: j.r.terhorst@uvt.nl, phone: +31 13466 8211, fax: +31 134662875.

The authors would like to thank Marina Martynova and Luc Renneboog for access to the Martynova-Renneboog corporate governance database and Alan Coen, Esther Eiling, Laura Veldkamp, Marta Szymanowska and participants in the INFINITI Conference on International Finance 2006 for helpful comments. 


\section{Introduction}

Despite well documented gains from international diversification, investors continue to have a strong preference for domestic assets. For instance, French and Poterba (1991) document that US equity traders allocate nearly $94 \%$ of their funds to domestic equities, even though the US equity market comprises less than $48 \%$ of the global equity market. Using two decades of data in a simple meanvariance optimization exercise, Lewis (1999) and Britten-Jones (1994) estimate that the US investor's optimal weight on foreign assets is about $40 \%$. This tendency to overinvest in domestic stocks, now dubbed the 'home bias puzzle' is not only a US phenomenon, but has been observed in nearly all other markets as well (see e.g. French and Poterba (1991), Cooper and Kaplanis (1994), and Tesar and Werner (1995). Lewis (1999) mentions costs of home bias due to forgone gains from international diversification in the range of $20 \%$ to almost double of lifetime (permanent) consumption.

Academics have come up with a host of possible explanations for the home bias puzzle. The prime targets were transaction costs such as fees, commissions and higher spreads (see e.g. Tesar and Werner (1995), Glassman and Riddick (2001) and Warnock (2001)) and direct barriers to international investment (see e.g. Black (1974), Stulz (1981) and Errunza and Losq (1981)). Evidence in Tesar and Werner (1995) and more recently Glassman and Riddick (2001) and Warnock (2001), however, rules out transaction cost as an important driver of the equity home bias. Moreover, the home bias puzzle persists even in times when most direct obstacles to foreign investment have disappeared. Important contributions focus on differences in the amount and quality of information between domestic and foreign stocks (see e.g. Gehrig (1993) and Brennan and Cao (1997)), on hedging of non-traded goods consumption as a motive for holding domestic securities (see e.g. Adler and Dumas (1983), Stockman and Dellas (1989) and Cooper and Kaplanis (1994)), and more recently on psychological or behavioral factors (see e.g. Huberman (2001), Coval and Moskowitz (1999), and Grinblatt and Keloharju (2000)). However, also these alternative explanations do not fully account for the observed home bias in international financial markets (see Ahearne, Griever, and Warnock (2004) among others).

Any meaningful explanation of the equity home bias requires a correct characterization of the benchmark weights, i.e. those to which actual holdings can be compared. Most studies have conveniently assumed that asset returns are well described by the International Capital Asset Pricing Model (ICAPM), in which case the benchmark weights are simply given by the proportion each country has in the global equity market portfolio. Another stream of papers has generated benchmark weights from a mean-variance optimization with sample estimates of the mean and covariance matrix of asset returns as inputs. Both approaches are, however, not without problems. In the first 'model-based' approach, investors are assumed to have a dogmatic belief in the I-CAPM, despite the reasonable doubt about the validity of the model, given its well known strict assumptions. The 'data-based' approach on the 
contrary completely ignores asset pricing models, and calculates weights in a standard mean-variance framework by relying solely on returns data. An important disadvantage of this approach is that the weights are extremely sensitive to the assumed vector of expected returns, an input that is notoriously difficult to estimate(see Merton (1980). Given that both approaches often yield very different benchmark weights means that measures and explanations of the equity home bias will be very sensitive to whether the first or the second approach is chosen.

A first contribution of this paper is that we allow investors to have a degree of skepticism about either modeling approach. We accomplish this by using the Bayesian portfolio selection frameworks recently developed by Pástor and Stambaugh (2000), Pástor (2000) and Garlappi, Uppal, and Wang (2004). Pástor (2000) investigates to what extent optimal portfolio weights vary with various degrees of mistrust in the asset pricing model. In this Bayesian framework, the investor is neither forced to accept unconditionally the pricing relation nor discard it completely in favor of the data. As the degree of scepticism about the model grows, the resulting optimal weights move away from those implied by the 'model-based' to those obtained from the 'data-based' approach. While this methodology typically produces weights that are much more stable over time compared to the 'data-based' approach, its reliance on sample data for higher levels of model uncertainty means, however, that extreme and volatile weights cannot be ruled out. To address this, we apply the volatility correction technique developed by Garlappi, Uppal, and Wang (2004). Their methodology extends the standard meanvariance framework as to also include estimation risk by restricting the expected return for each asset to lie within a specified confidence interval around its estimated value, rather than treating the point estimate as the only possible value, i.e. they allow for multiple priors. Investors' aversion to uncertainty is taken onboard by allowing investors to minimize over the choice of expected returns and/or models.

In total, we calculate measures of the equity home bias for a sample of 25 countries using 5 frameworks, namely (1) the I-CAPM , (2) 'data-based' standard mean-variance optimization, (3) the Bayesian approach of Pástor (2000), (4) the Multi-Prior technique of Garlappi, Uppal, and Wang (2004) applied to the 'data-based' approach and (5) the same volatility correction mechanism of Garlappi, Uppal, and Wang (2004) combined with the Bayesian approach of Pástor (2000). In line with other empirical evidence (see Pástor (2000), Li (2002), and Asgharian and Hansson (2005)), we find that reasonable degrees of mistrust in the model lead to lower, yet mostly positive, levels for home bias measures. In a panel of 25 developed and emerging markets we find that average Bayesian home bias is lower by $30 \%$ if we depart from the rather restrictive prediction of the I-CAPM. In the case of the Netherlands for instance, a plausible degree of mistrust in I-CAPM leads to a sharp decrease in home bias which is fully eliminated in the days of the common currency.

A second contribution of this paper is that we relate the various home bias measures to a large set of explanatory variables. We consider several proxies for the continuing process financial market 
integration and factors relevant to the investment decision such as indicators of performance and development of the stock market, financial structure, international trade and investment exposure as well as corporate governance improvements. We conjecture that globalization and regionalization processes erode the potential causes of home bias through their impact on barriers to cross-border equity trade, transaction costs, information and perceptions asymmetries. We observe that the recent surge in international integration appears to challenge the puzzle through both its global and regional components. Time, which we interpret as a proxy for global phenomena (such as integration, technological and financial development) appears to work consistently against home bias. Besides a moderate negative trend, we find a sharp bias correction effect linked to the European Monetary Union. Increased foreign participation of Euro Area countries may be directed either towards more attractive European markets due to lower transaction costs and exchange rate risk or outside the European space as a reaction to higher market co-movements in the area. The downward evolution of home bias is consistent across several measures and gives additional weight to our conjecture that market integration erodes home bias.

The remainder of this paper is structured as follows. Section 2 reviews theoretical considerations related to computing optimal investment weights. Section 3 presents the dataset and the methodology for computing the home bias. Section 4 reports our empirical results concerning the home bias, while Section 5 examines the sensitivity of the time-varying measures of home bias to several integration proxies and factors relevant to international investment decisions. Finally, Section 6 summarizes our main findings.

\section{Optimal Portfolio Weights}

In this section, we discuss alternative ways to calculate theoretically optimal portfolio weights with which observed weights can be compared. Section 2.1 summarizes the standard mean-variance model of portfolio choice. Section 2.2. discusses the International CAPM. Sections 2.3 and 2.4. discuss the Bayesian modelling approaches of Pástor (2000) and Garlappi, Uppal, and Wang (2004), respectively.

\subsection{Classical Mean-Variance Portfolio Model}

The common starting point is the mean-variance framework of Markowitz (1952) and Sharpe (1963) where the investor makes his portfolio choice in order to maximize his expected utility,

$$
\max _{\omega} \omega^{\prime} \mu-\frac{\gamma}{2} \omega^{\prime} \Sigma \omega,
$$

where $\omega$ is the $N$-vector of portfolio weights allocated to $N$ assets, i.e. domestic and foreign equity

holdings $(N=2), \mu$ is the $N$-vector of expected returns, $\Sigma$ is the $N \times N$ variance-covariance matrix and 
$\gamma$ is the coefficient of relative risk aversion. Under the assumption that $\omega^{\prime} \iota=1$ (the budget constraint), the solution of the portfolio problem becomes

$$
\omega^{*}=\frac{1}{\gamma} \Sigma^{-1}(\mu-\eta \iota)
$$

where $\eta$ denotes the expected return on the zero-beta portfolio corresponding to the optimal portfolio and $\iota$ is a $N$-vector of ones. The budget constraint effectively fixes $\gamma$ for a known value of the zero-beta expected return through $\gamma=\iota^{\prime} \Sigma^{-1}(\mu-\eta \iota)$ and determines uniquely the optimal portfolio weights (De Roon and Nijman (2001)). If a risk-free rate is available and chosen as the zero-beta portfolio, the

coefficient of risk aversion becomes $\gamma=\iota^{\prime} \Sigma^{-1} \mu_{e}$, where $\mu_{e}$ is the vector of the expected excess returns (over the risk-free rate). The analytical portfolio choice solution in the mean-variance framework, when short sales are allowed is:

$$
\omega^{*}=\frac{\Sigma^{-1} \mu_{e}}{\iota^{\prime} \Sigma^{-1} \mu_{e}}
$$

The solution of the optimization problem involves the true (unobserved) expected returns and variance-covariance matrix of the returns. Available returns data enables us to use the sample moments as estimates of the true parameters. Merton (1980) shows that sample variance-covariance matrix is an accurate estimate of the true parameter but the estimation of the expected returns based on historical data is very unreliable due to the high volatility of returns. The impact of the mean estimated imprecisely, is amplified in the context of portfolio choice, as the inverse of the variance-covariance matrix tends to be a large number when the correlations between the countries are high (Jenske (2001)). Therefore, the 'data-based' approach (i.e. substituting the sample mean and variance in the equation 3) directs investors to take extreme and volatile positions.

\subsection{International CAPM}

An asset pricing model, such as the International Capital Asset Pricing Model (I-CAPM), provides an alternative to the 'data-based' approach. The I-CAPM is valid in a perfectly integrated world, where the law of one price holds universally and markets clear (total wealth is equal to total value of securities). The world market portfolio can then be defined as the sum of all individual portfolios weighted by the positions held by mean-variance investors. The portfolio implication of the CAPM is that the average mean-variance investor holds the market portfolio (Lintner (1965)). In an international setting, the optimal investment weights of a country according to this so-called 'model-based' approach, are given by the relative shares of domestic and foreign equities in the world market capitalization. For a US investor this implies that domestic equity holdings should have been about $40 \%$ in 2004 . The actual domestic allocations figures for the US were as high as $80 \%$. 
The I-CAPM results in the well-known linear beta relationship between risk premium on the domestic portfolio and the expected excess return on the world market benchmark ${ }^{1}$ :

$$
E\left(r_{d}\right)-r_{f}=\beta_{d w}\left[E\left(r_{w}\right)-r_{f}\right]
$$

where $r_{d}$ is the real return on the domestic market portfolio, $r_{f}$ is the risk free rate, $\beta_{d w} \equiv \frac{\operatorname{cov}\left(r_{w}, r_{d}\right)}{\operatorname{var}\left(r_{w}\right)}$ is the world beta of the domestic market and $r_{w}$ is the return on the world market portfolio. The empirical counterpart of equation 4 is given by

$$
r_{d}-r_{f}=\alpha+\beta_{d w}\left(r_{w}-r_{f}\right)+\varepsilon
$$

where $\alpha$ and $\varepsilon$ are respectively the intercept and the disturbance term. The I-CAPM is considered valid if estimates of the intercept, $\hat{\alpha}$ are zero. An intercept different than zero, even if insignificant, can be used by a Bayesian investor to question the optimality of the portfolio prediction of the I-CAPM.

\subsection{Bayesian Mean-Variance Portfolio Weights}

Considering the stringency of the assumptions of the I-CAPM, it is reasonable to expect that some investors do not accept the model unconditionally. When the I-CAPM holds, the world benchmark fully describes the asset returns and captures all sources of priced risk. In terms of the beta pricing relationship (5), a valid model results in a zero value for the intercept $\hat{\alpha}$. In the Bayesian framework developed by Pástor (2000), when there is mistrust in the I-CAPM, the data becomes informative and is involved in the portfolio allocation decision. The degree of trust (i.e. the belief that the intercept $\hat{\alpha}$ is zero) is expressed in values of the standard errors of the intercept $\sigma_{\alpha}$. A small value indicates a strong belief that the theoretical model is valid and results in optimal portfolio weights that closely correspond to the 'model based' approach. A higher value involves data to a larger extent in the computation of optimal weights leading thus to a different set of optimal weights and brings us closer to the results of the 'data based' approach. Full mistrust in the model (i.e. $\sigma_{\alpha} \rightarrow \infty$ ) coincides with the 'data based' optimal weights. This Bayesian interpretation is an insightful reconciliation of the 'model' and 'data-based' approaches. For instance, a nonzero value for $\hat{\alpha}$, even if insignificant according to a standard $t$-test (and therefore failing to reject the I-CAPM), could become instrumental in explaining why observed allocations deviate from the model prescriptions.

The starting point of the Bayesian analysis is a prior (non-data) belief in the the model, in this case, the belief in a zero intercept and no mispricing. The prior is updated using returns data to a certain extent depending on the chosen degree of mistrust in the model. The sample mispricing, $\alpha$ is "shrunk" accordingly towards the prior mean of $\alpha$ to obtain the posterior mean of $\alpha$.

\footnotetext{
${ }^{1}$ This model makes the additional assumption that currency risk is not priced. See De Santis and Gérard (2006) and Fidora, Fratzscher, and Thimann (2006) for an analysis of exchange rate risk on home bias measures.
} 
Using the data in combination with the model prediction ultimately results in different estimates for the mean and variance covariance matrix of returns, as now the moments of the predictive distribution are used to compute the portfolio weights. These Bayesian mean-variance optimal weights are computed as:

$$
\omega^{*}=\frac{\Sigma^{*-1} \mu_{e}^{*}}{\iota^{\prime} \Sigma^{*-1} \mu_{e}^{*}}
$$

where $\mu_{e}^{*}$ and $\Sigma^{*}$ are the predictive mean and variance that replace in this approach the sample moments of the distribution of returns.

The predictive density of returns (entering the utility function of the investor that maximizes next period wealth)is defined as:

$$
p\left(r_{t+1} \mid \Phi\right)=\int_{\theta} p\left(r_{t+1} \mid \theta, \Phi\right) p(\theta \mid \Phi) d \theta
$$

where $p\left(r_{t+1} \mid \Phi\right)$ is the probability density function of excess returns conditional on $\Phi$ (the sample data) and $\theta$ is the set of parameters of the statistical model that describes the stochastic behavior of asset returns. To treat the estimates of the parameters $\hat{\theta}$ as the true values, is to ignore estimation risk. An alternative is to use Bayesian analysis to account for estimation risk. The predictive density (equation 7) involves $p(\theta \mid \Phi)$, the conditional probability of the parameters of the model given the data available. According to Bayes' Rule, the posterior density, $p(\theta \mid \Phi)$, is proportional to the product of the likelihood function, or probability distribution function for the data given the parameters of the model, $p(\Phi \mid \theta)$, and the prior density, $p(\theta)$, that reflects the non-data information available about $\theta$ (Koop (2003)):

$$
p(\theta \mid \Phi) \propto p(\Phi \mid \theta) p(\theta)
$$

In our setting, the prior of zero intercept follows from assuming a valid I-CAPM and is subsequently updated through incorporation of the information revealed by the data. The methodology and the analytical solutions for the mean and variance of the predictive density are presented in further detail in Appendix A.

A degree of mistrust in the I-CAPM depending on the empirical performance of the model on specific country data, may result in optimal weights that are closer to the observed allocations and thereby imply for certain countries, a lower home bias than the deviation from the market capitalization share.

\subsection{Bayesian Multi-Prior Framework}

The Bayesian approach presented above uses the I-CAPM as the starting point and departs from its prediction in proportion with the investors' degree of mistrust in the model. Larger mistrust in the ICAPM makes historical return data more relevant in estimating the optimal allocations, which become in turn, more volatile. In the extreme 'data-based' case, relying on the sample mean and variance on 
thirty years of returns data, we obtain that over the 1980s, the US investor should have alternated selling foreign or domestic assets short. In early 1990s, the optimal investment strategy based on the sample data would have been for the US investor to short sell domestic assets. Imposing short sales constraints, the average of optimal domestic holdings for the US investor is an unrepresentative $31 \%$. Garlappi, Uppal, and Wang (2004) tackle the problem of volatile data by extending the mean-variance framework to incorporate the investors' aversion to uncertainty around the estimate of the mean returns. This changes the standard mean-variance problem in two ways: (1) it binds the expected returns to a confidence interval around their estimate, thus taking into account the eventual estimation error and (2) it allows the investor to minimize over the choice of expected returns, thus manifesting its aversion to uncertainty. The multi-prior framework of Garlappi, Uppal, and Wang (2004) is defined by the following problem:

$$
\max _{\omega} \min _{\mu} \omega^{\prime} \mu-\frac{\gamma}{2} \omega^{\prime} \Sigma \omega
$$

subject to

$$
\begin{gathered}
f(\mu, \hat{\mu}, \Sigma) \leq \epsilon \\
\omega^{\prime} \iota=1
\end{gathered}
$$

where $\hat{\mu}$ is the sample mean of asset returns. If the confidence intervals are defined jointly for all assets,

$f$ can be taken as $\frac{T(T-N)}{(T-1) N}(\hat{\mu}-\mu)^{\prime} \Sigma^{-1}(\hat{\mu}-\mu)$ and $\epsilon$ as a quantile for the $F$-distribution ${ }^{2}$, where $N$ is the number of assets and $T$, the number of observations. The constraint translates into $P(f \leq \epsilon)=1-p$ for a corresponding probability level. This framework can also be extended to include uncertainty over a chosen return-generating model, such as the I-CAPM. The solution to the Multi-Prior max-min problem is a set of optimal weights with considerably smoother behavior compared to the ones obtained through the direct influence of the data. Appendix B presents the analytical results obtained by Garlappi, Uppal, and Wang (2004) for the case when short sales are allowed.

\section{Home Bias Measures and Data Issues}

The previous section presented alternative ways of defining optimal portfolio allocations. This section introduces our measure of home bias in terms of actual and optimal portfolio weights, as well as the main characteristics of the dataset used.

\footnotetext{
${ }^{2}$ If asset returns are normally distributed and $\Sigma$ is known, $f$ has a $\chi^{2}$ distribution with $N$ d.f. If $\Sigma$ is not known, it follows a $F$-distribution with $N, T-N$ d.f. (Garlappi, Uppal, and Wang (2004))
} 


\subsection{Home Bias Measures}

We quantify the home bias of country $i$ as the relative difference between actual $\left(A C T_{i}\right)$ and optimal $\left(O P T_{i}\right)$ foreign portfolio weights:

$$
H B_{i}=1-\frac{A C T_{i}}{O P T_{i}}
$$

Optimal portfolio weights are calculated using the alternative methodologies described in Section 2. The actual portfolio holdings $\left(A C T_{i}\right)$ are determined using data from the International Investment Position (reported to the IMF as part of the Balance of Payments). More specifically, the share of foreign equity in the total equity portfolio of country $i$ is computed as the ratio of its foreign equity holdings $^{3}\left(F A_{i}\right)$ and the total (foreign and domestic) equity holdings. The domestic equity holdings are calculated as the difference between the market capitalization of the country $\left(M C_{i}\right)$ and the total domestic equity stocks held by foreign investors ${ }^{4}\left(F L_{i}\right)$ :

$$
A C T_{i}=\frac{F A_{i}}{F A_{i}+M C_{i}-F L_{i}} .
$$

In the typical case, when actual foreign involvement is lower than the optimal share of international assets, and the country is subject to home bias, the measure takes values between 1 (when the investors hold only domestic assets) and 0 (when actual and optimal portfolio weights are equal). For instance, if a country should optimally hold $80 \%$ of its portfolio in foreign stocks and has an actual allocation of $20 \%$, its home bias reaches 0.75 . However, at times, the data might offer cases when the actual weights exceed optimal weights, for instance when negative or very low weights are assigned to the world market index in the optimization framework. This can be the case when the world market index has a high variance and covariance with the domestic index and with a lower mean. In such instances the country appears not home biased, but on the contrary, overinvesting abroad and the former measure of home bias would be misleading. Therefore, we modify the formula to take into account the case of overinvestment abroad (negative 'home bias') and obtain comparable results, as follows:

$$
H B_{i}=\frac{\min \left(\left|O P T_{i}\right|, A C T_{i}\right)}{\operatorname{sign}\left(O P T_{i}\right) \max \left(\left|O P T_{i}\right|, A C T_{i}\right)}-1 .
$$

We use this formula to compute a negative measure of 'home bias' when optimal allocations are lower than the observed foreign investment. For example, if actual foreign holdings are $20 \%$ and the optimal weight in foreign assets is $1 \%$, the negative 'home bias' is -0.95 . This extended formula has a lower bound at -1 for the cases when the optimal foreign stock holdings are zero. It achieves values below -1 when short sales are allowed and optimal strategies result in negative weights for the world market index. In this range, home bias is no longer monotonically increasing in the difference between optimal and actual weights. If actual foreign holdings are $20 \%$ while the optimal weight is $-5 \%$, the

\footnotetext{
${ }^{3}$ Reported in International Investment Position / Assets / Portfolio Investment / Equity

${ }^{4}$ Reported in International Investment Position / Liabilities / Portfolio Investment / Equity
} 
resulting negative 'home bias' value is -1.25 . By construction, this formula also smoothes out the effect of any extreme values in the optimal weights. For instance, if a country should optimally sell short foreign equities (in proportion of -500\%) and holds $20 \%$ in foreign assets, the corresponding negative 'home bias' is -1.04. A negative value implies that the country is overinvesting abroad and a value lower than -1 , indicates that short sales of foreign equities are optimal.

\subsection{Data and Possible Biases}

We investigate the home bias behavior of 25 countries of which 19 are European: Austria, Belgium, Czech Republic, Denmark, Finland, France, Germany, Greece, Hungary, Iceland, Italy, The Netherlands, Poland, Portugal, Spain, Switzerland, Sweden, United Kingdom, Turkey and 6 form a non European control group: Australia, Canada, Hong Kong, Japan, New Zealand and United States. The variation of this group, combining developed as well as emerging countries, members of European Union (EU) and European Monetary Union (EMU) together with outsiders, is useful for isolating any EU/euro effect in the evolution of home bias. However, the heterogeneity of the sample results into an unbalanced panel, with distinctively better data coverage for the more developed countries. Several types of data serve our analysis. First, we compute weekly Dollar-denominated total returns for the 25 countries as well as for the global market portfolio over the period January 1973 - December 2004 based on Datastream's total market indices. For a number of countries, data is only available after January 1973 (see first column of Table 2). The risk-free rate is the one-month Treasure Bill rate from Ibbotson and Associates Inc., available on Kenneth French's website ${ }^{5}$. Market capitalization figures are obtained from Datastream (for developed countries) and Standard \& Poor's Emerging Markets Database, respectively.

Second, we calculate actual portfolio weights based on the International Investment Position (IIP) in foreign portfolio assets and liabilities (a chapter of the Balance of Payments) recorded with annual frequency in the IMF's International Financial Services database. The IIP is defined by the IMF as a balance sheet of a country's stock of financial assets and liabilities at the end of year. It distinguishes between direct investments, portfolio investments (holdings of less than $10 \%$ of the share capital of the company) and other investments (including financial derivatives). Table 1 presents average portfolio holdings of foreign assets and liabilities (in millions USD) for the 25 countries in our dataset for the full sample as well as for half samples. For all countries, without exception, average foreign assets and liabilities increase dramatically in the second half of the sample, suggesting a boom in international portfolio exposure over the 1990s. Some countries in our sample take clear net positions of in the international financial markets. Foreign assets holdings are several times higher than liabilities in

\footnotetext{
${ }^{5}$ http://mba.tuck.dartmouth.edu/pages/faculty/ken.french/data_library.html
} 
Belgium, Iceland, Italy, Canada and New Zealand. Net receivers are Czech Republic, Denmark, Finland, Greece, Hungary, Poland, Spain and Turkey. Market capitalization figures (as percentages from the world market) are relatively stable, though there is a discernable shift from US, Japan and Canada towards the European countries in the relative market shares. The data shows that the trend in the home bias measure that takes I-CAPM as the benchmark reflects the evolution of actual rather than optimal foreign allocations. The information on IIP presented above is gathered during periodical benchmark surveys, conducted by the government to obtain the current value of domestic holdings of foreign securities, surveys that take place several years apart. The yearly figures presented in IIP are estimated stocks based on the transactions involving non-residents, which are reported yearly to the central government according to the Balance of Payments accounting and the periodical benchmark surveys. Data on capital flows, or transacting data, are then used to extrapolate the foreign investment positions in the years between surveys (Tesar and Werner (1995)). IMF has conducted Coordinated Portfolio Investment Surveys (CPIS) in 1997 and 2001 for 29, respectively 64 countries, in which most countries take an aggregate approach and report foreign holdings by country in a reliable fashion. The IIP data is a virtually unique source for international portfolio holdings of relatively wide geographical and temporal coverage. However, there are several possible in-built biases associated with it. The eventual biases that have been identified in the literature may arise in several situations. First, if a foreign subsidiary located in the reference country invests (for the ultimate benefit of its foreign owner) in a third country, the reference country appears as the foreign investor and not the country of the parent company. Also, the accuracy of data collection (Tesar and Werner (1995)) and the choice of price index used for revaluation in estimating IIP holdings (Griever, Lee, and Warnock (2001)) can be questioned. Warnock (2001) points out that use of a 1994 benchmark survey in US to re-estimate positions in foreign holdings for the previous years led to serious upward corrections with consequently lower figures for home bias. However, given that the frequency of surveys increases, the chances of significant backward corrections in the future are lower.

The third type of data we use consists of development and financial indicators that are based on data from International Financial Services and on the updated version of the database on the structure and development of the financial sector compiled by Beck, Demirgüç-Kunt, and Ross (2000).

Last, we use the shareholder protection index from the Martynova-Renneboog corporate governance database, an index increasing in the power of shareholders to mitigate opportunistic behavior of managers. The index is available for the period 1990-2004 for all European countries in our sample except Turkey and for the US (see Goergen, Martynova, and Renneboog (2005)). 


\section{Empirical Analysis}

The last decade has been associated with increased international openness for most participants to the world financial market. This phenomenon is reflected in the upward trend of actual foreign holdings which influences directly the measurement of home bias. We obtain series of home bias from a number of alternative investment benchmarks. The analysis revolves around the accuracy of the I-CAPM as the return generating model and Section 4.1 presents the results of testing the I-CAPM for the countries in our dataset. In Section 4.2 we compare the evolution of time series of different home bias measures computed in the traditional I-CAPM perspective and alternatively using the Bayesian approach of Pástor (2000) and the Multi-Prior correction of Garlappi, Uppal, and Wang (2004).

\subsection{I-CAPM}

Most previous studies have assumed that the I-CAPM provides a reasonably good description of the data. According to this model, the optimal domestic allocation equals the relative market capitalization share of a country in the global market portfolio. More concretely, this means that domestic allocations should not increase $10 \%$ for any European country. Similarly, from the 25 countries in our sample, only Japan and the US can justify higher domestic allocations, of respectively about $20 \%$ and $40 \%$ respectively. In this section, we investigate whether this dogmatic belief in the I-CAPM is warranted by testing whether the intercept $\alpha$ in the empirical I-CAPM specification is statistically different from zero or not. Table 2 summarizes the main test results ${ }^{6}$. All markets are positively and significantly related to global market shocks. Beta estimates range from 0.08 in Iceland to 1.09 in Finland. The global market shocks explain a considerable proportion of local market returns (on average 23\%), except in Iceland (1\%), Turkey (5\%), and Austria (9\%). More interesting for the purpose of this paper are the point estimates and standard errors for the alphas. We note a number of interesting findings. First, the alphas are not statistically significant from zero in all countries except Iceland and Turkey. In other words, we cannot reject the I-CAPM for 23 of the 25 countries. Second, while not being statistically different from zero, the alphas are predominantly positive (all countries except Germany, Switzerland, and Japan). Positive alpha make domestic investment more attractive to investors who have incomplete thrust in the I-CAPM, and should hence contribute to lower measures of the equity home bias. Similarly, negative alphas will induce such investors to take a domestic position that is lower than the country's weight in the global market portfolio. This effect is likely to be especially strong for Japan, given that its alpha is strongly negative $(-0.06)$. Third, the alphas typically have a large standard error, ranging from 0.02

\footnotetext{
${ }^{6}$ The Bayesian approaches need to first two years of data to compute the Bayesian prior information. To facilitate comparison between results from Bayesian and non-Bayesian models, we exclude the first two years of data even for the non-Bayesian approaches.
} 
for the US to more than 0.10 for the Czech Republic, Finland, Greece, Hungary, Poland, and Turkey. Recall from Section 2 that the Bayesian approaches take the standard error on the alphas as an indicator of the degree of mistrust in the I-CAPM. A high degree of mistrust means that the optimal weights will deviate more from the I-CAPM, towards those obtained from a 'data-based' standard mean-variance optimization using sample estimates. In the following section, we compare the home bias measures obtained from the I-CAPM weights with those determined by the Bayesian approach of Pástor (2000) and the Multi-Prior correction of Garlappi, Uppal, and Wang (2004).

\subsection{Home Bias Measures}

We compute optimal portfolio holdings and home bias under five optimization frameworks. The first case is traditional in the home bias literature and assumes that I-CAPM is a valid description of the data. Optimal holdings are given by the relative country shares in the world market capitalization. The second case follows a pure 'data-based' approach, where the sample moments are substituted in the solution to the mean-variance portfolio choice problem. The third case is the Bayesian conciliation of the first two, proposed by Pástor (2000), where a certain degree of mistrust in the model is taken into account to determine the predictive moments of distribution. These are substituted in the analytical solution of the mean-variance optimal weights. The remaining two alternative measures of home bias result from applying the Multi-Prior correction of Garlappi, Uppal, and Wang (2004) to the pure databased approach and to the Bayesian approach respectively in order to obtain smoother series. In the latter case, the predictive moments of distribution rather than the sample estimates are used in the Multi-Prior optimization setting.

Table 3 reports descriptive statistics of the home bias measures obtained using these five different approaches. Figures 1 to 4 plot these alternative home bias measures over time for all 25 countries in our sample. The reported results are based on models without short-sales constraints. Qualitatively similar results are found when short-sales are imposed. We observe a number of interesting patterns.

First, the I-CAPM based home bias measures confirm that investors predominantly invest in domestic assets. The bias ranges from 0.55 in Belgium to more than 0.98 in Greece, Poland, and Turkey. Notice that the latter equity markets are among the most volatile in our sample, i.e. by not geographically diversifying their equity portfolios, these investors bear a substantial amount of country-specific (and hence not rewarded) risk. Between those two extremes, we find that most countries exhibit an average home bias around 0.70-0.80.

Second, we find that the 'data-based' approach leads to a substantial reduction in measures of the equity home bias. When investors are supposed to have full confidence in the I-CAPM, the average home bias (over time and across countries) amounts to 0.80 . If, on the other hand, the investors have no 
confidence at all in the I-CAPM, and hence follow a purely 'data-based' approach, the measures average home bias drops to 0.42 , a decrease of nearly $50 \%$. In Belgium, Greece, Iceland, the Netherlands, and the UK, the home bias even drops below 0.10. As pointed out by Merton (1980), a disadvantage of the data-based approach is that it leads to extreme and volatile investment positions. Our results are no exception, as can be seen from the high standard errors on the home bias measure (about 7 times higher than in the I-CAPM case).

Third, we find that allowing for a reasonable degree of mistrust ${ }^{7}$ in the I-CAPM leads to a substantial reduction in the home bias measures. More concretely, the home bias drops to 0.51 when Pástor's Bayesian approach is used (or with 36\%) and to about 0.68 in case the multi-prior method of Garlappi, Uppal, and Wang (2004) is applied (or with 15\%). Notice that we already observe this decrease in the home bias for a relatively moderate degree of mistrust in the I-CAPM. The partial reliance of Pástor's method on sample data leads to occasionally unstable optimal weights, and hence home bias measures. A large part of this variability disappears when the Multi-Prior approach of Garlappi, Uppal, and Wang (2004) is used, i.e. when expected returns are restricted to a certain interval and investors minimize over the choice of expected returns. Home bias estimates using this approach are higher compared to the 'data-based' and Pástor's method, but still about 15\% lower compared to those implied by the I-CAPM.

Fourth, we observe a substantial decrease in the I-CAPM equity home bias for most countries, especially in the 1990s. Interestingly, the decrease is more pronounced when the alternative models to the I-CAPM are used. In fact, assuming a reasonable degree of mistrust in the I-CAPM minimizes home bias in Austria, Denmark, Iceland, The Netherlands and the UK. In some other countries, like the Czech Republic, Poland and Japan, the home bias measures are largely unaffected by the way the home bias is measured.

\section{The Link between Financial Market Integration and Home Bias}

In the previous section, we showed that the equity home bias remains substantial for many of the countries in our sample, even when we allow for a reasonable degree of mistrust in the I-CAPM. At the same time, we observe a downward trend in the home bias for many countries. The aim of this section is to increase our understanding of the dynamics and drivers of changes in the equity home bias.

\footnotetext{
${ }^{7}$ The Bayesian home bias results are reported for a value of $\sigma_{\alpha}^{2}$ of 0.05 , which corresponds to the higher levels of the standard errors reported in the previous subsection. In computing the Multi-Prior home bias the value of $\epsilon$ (the bound on the added constraint) is chosen so that the percentage size of the confidence interval for $F_{N, T}$ implied by $\epsilon$ is $90 \%$. This rather high value results in substantial smoothing of the optimal portfolio weights and subsequently of home bias figures.
} 


\subsection{Hypotheses}

Increasing financial integration arises as a key candidate to explain the observed decrease in the equity home bias. In integrated equity markets, investors can trade international equities freely and at low cost. Similarly, deeper financial and also economic integration contributes to a lower information asymmetry gap between foreign and domestic investors. The home bias may erode further with improved quality of corporate governance (see e.g. Kho, Stulz, and Warnock (2006)). While further integration also tends to increase cross-market correlations (see e.g. Baele (2005), Bekaert, Hodrick, and Zhang (2005), Bekaert and Harvey (2000), Bekaert and Harvey (1997) and Longin and Solnik (1995), the benefits from international diversification continue to be large (see e.g. Heston and Rouwenhorst (1994), Griffin and Karolyi (1998), Baele and Inghelbrecht (2006)). A first hypothesis is whether further integration has reduced the equity home bias. To test this hypothesis, we use three integration proxies. First, we proxy integration with a simple linear time trend. While admittedly a crude measure, it has the advantage of being simple and easy to interpret. Second, we take the time-varying global market beta as an alternative integration proxy. This measure has recently gained popularity as an indirect integration indicator (see e.g. Bekaert and Harvey (2000), Bekaert and Harvey (1997), Fratzcher (2002), Baele (2005), Baele, Ferrando, Hördahl, Krylova, and Monnet (2004), and Eiling, Gerard, and De Roon $(2004)))$. These papers present strong evidence that global (regional) market betas tend to increase with integration. Here, we use the end-of-year global market beta estimated from weekly data. Third, we use the ratio of a country's import plus export over GDP and alternatively the sum of a country's foreign direct investments (assets and liabilities) scaled by GDP as indicators of international exposure of a country. Previous research has found this variables to be a good proxy not only for economic but also for financial integration (see e.g. Bekaert and Harvey (1995), Chen and Zhang (1997) as well as Lane and Milesi - Ferretti (2003) for a more detailed discussion). In addition, the information carried by both international trade and foreign direct investments should make investors more familiar with foreign stocks, and should reduce the (perceived) information disadvantage (see e.g. Lane and Milesi Ferretti (2003)).

A second hypothesis we want to test is whether the home bias decreased faster in the European (Monetary) Union compared to the rest of the world. Over the last two decades, this region has gone through a period of extraordinary economic, financial, and monetary integration culminating in the introduction of the euro in January 1999. We further distinguish between countries that have introduced the single currency and those that have opted out. We differentiate between euro and non euro area countries for a number of reasons. First, due to the single currency, at least within the euro area, the EU currency matching rule, which required insurance companies and pension funds, among others, to match liabilities in a foreign currency for a large percentage by assets in the same currency, is 
de facto eliminated. Second, indicators of financial integration have increased faster in Europe relative to the rest of the world. Baele and Inghelbrecht (2006) found for a sample of 21 countries that global and regional market betas have increased relatively faster for European countries. In a study related to ours, De Santis and Gérard (2006) find that Euro Area investors have a strong preference for stocks and bonds in other Euro Area countries, indicative of strong regional integration. Third, by investigating the differential impact of the euro on home bias, we contribute to the stream of literature trying to determine the contribution of forming a currency union on (regional) financial integration.

Third, we investigate whether home bias exhibits $\beta$-convergence. Adam, Jappelli, Menichini, Padula, and Pagano (2002) borrow this concept from the growth literature to measure the speed of adjustment of deviations of countries to their prior values. We test for $\beta$-convergence by estimating the response of the growth rate of home bias in the current year to the level of home bias in the previous

year. A negative coefficient indicates convergence and its size can be interpreted as the speed of the convergence process.

\subsection{Control Variables}

We test our main hypotheses in the presence of a set of control factors relevant to international portfolio choice of which include:

1. Country-Specific Risk Country-specific risk is defined as the volatility of the residuals from a I-CAPM regression on the respective country returns. Investors fully in the home market bear not only systematic but also country-specific risk. Because the latter risk is not compensated by higher expected returns, the incentives for investors to diversify internationally, i.e. to decrease their home bias, increase with the level of country-specific risk. Alternatively, country-specific risk may just be an instrument for time-varying market integration. Baele and Inghelbrecht (2006)for instance find that further integration in Europe did not only lead to increasing global and regional market betas, but also to lower average country-specific risk. If the latter effect dominates, one would expect a positive relationship between country-specific risk and the equity home bias.

2. Equity market Development We proxy equity market development by the ratio of stock market capitalization to $\mathrm{GDP}^{8}$. Larger equity markets (relative to the real economy) tend to have lower costs of financial intermediation, higher liquidity, and better investment opportunities (see e.g. Levine and Zervos (1996)). On one hand, increasing market development makes the local market more attractive to foreign investors, which should have a negative effect on the equity home bias. Alternatively, domestic investors have ceteris paribus less incentives to diversify their investment

\footnotetext{
${ }^{8}$ Qualitatively similar results were obtained when we use market liquidity measures, such as the ratio of market turnover over market capitalization, instead of the ratio of market cap over GDP.
} 
portfolios in large and well developed markets. The empirical analysis further on should reveal what effect dominates.

3. Bank Assets The ratio of deposit money bank assets to GDP can be taken as a proxy for the importance of bank finance in a reference country. A higher share of bank assets interpreted as a sign of lower financial diversity has been associated with less attractiveness for foreign investors (Mann and Meade (2002)). To the extent that there is a tradeoff between the bank and stock market development, international markets become a substitute for an underdeveloped domestic market. Moreover, financial intermediaries may contribute to raising the international awareness of domestic investors (Lane and Milesi - Ferretti (2003)).

4. Shareholder Protection Index The corporate environment may influence the investment decisions, by rendering a country more attractive to investors, especially considering the higher uncertainty associated with foreign equity investments. We use the shareholder protection index from the Martynova-Renneboog corporate governance database (see Goergen, Martynova, and Renneboog (2005)), as an indicator of the ability of shareholders to overcome agency problems.

\subsection{Model Specification}

We conduct panel data estimation allowing for fixed country effects and using a feasible GLS technique to control for cross-sectional heteroskedasticity, in the following framework:

$$
\Delta H B_{i t}=\alpha_{i}+\beta_{1} T I M E_{t}+\beta_{2} H B_{i t}(-1)+\beta_{3} I N T E G R A T I O N_{i t}+\beta_{4} E_{X P O S U R E}+\beta_{5} X_{i t}+\epsilon_{i t},
$$

where $\Delta H B_{i t}$ is the annual growth rate (in percentages) of home bias of country $i$, measured using the different methods presented in the previous section, $T I M E_{t}$ is a trend variable, $H B_{i t}(-1)$ is the level of home bias in the previous year in the country of reference, INTEGRATION ${ }_{i t}$ a proxy for market integration which is in turns is reflected by the time-varying world market betas $\left(B E T A S_{i t}\right)$ or an indicator function, $I_{i t}(E U / E M U)$ taking the value 1 if country $i$ is a member the European Union (respectively the European Monetary Union) at time $t$ and 0 otherwise, EXPOSURE is taken as the annual growth rate (in percentages) of the trade openness index of a country, measured as the ratio of the country's foreign trade (import and export) to the GDP $\left(O P N_{i t}\right)$, or the annual growth rate (in percentages) of foreign direct investments (assets and liability) scaled by GDP ( $F D I_{i t}$ ), and $X_{i t}$ is a set of control variables including: annual growth rate (in percentages) of the variance of the residuals from the I-CAPM regressions (IDSYNRISK $K_{i t}$ ), annual growth rate (in percentages) of the stock market capitalization of a country scaled by GDP $\left(S T M K T C A P_{i t}\right)$, annual growth rate (in percentages) of the deposit money bank assets of a country scaled by GDP $\left(D B A G D P_{i t}\right)$ as well as the Shareholder Protection Index (SHLDPROT $\left.T_{i t}\right)$. 


\subsection{Estimation Results}

We test the model presented in the previous section on three different measures of home bias, depending on the investment benchmark used: the I-CAPM home bias, the 'data based' and the Bayesian home bias. In the latter two cases we use the smoothed variables obtained by applying the correction methodology proposed by Garlappi, Uppal, and Wang (2004).

Table 4 presents the results for the first set of estimations, where the depended variable is the ICAPM home bias measure. First, we note a moderate negative trend, highly significant and virtually invariable across our specifications. Home bias adjusts downward at a speed increasing with a third of a percent per year. This linear decrease in the rate of change in home bias is an indication of the positive effect of universal factors, such as globalization and technological progress affecting more than financial markets.

The previous year level of home bias enters the regressions with a consistent negative sign, statistically significant at $1 \%$. Home bias exhibits $\beta$-convergence from a previous (higher) level at a speed ranging from a quarter to (nearly) a half of a percentage per year.

We test the relationship between the evolution of home bias and the continuing process of financial integration using several possible proxies for integration: time-varying world market betas as well as dummy variables constructed for EU and respectively EMU member states. We find evidence of a negative relationship between the percentage change in home bias and two of our proxies of integration. The process of deeper integration in the world financial markets, reflected in the increase of the world market betas of most of the countries in our sample over time is associated with a highly significant decrease in home bias. Interestingly, the same pattern of decreasing home bias is found within the Euro Area, but not in the broader European Union. While it is difficult to distinguish among the array of factors causing home bias, the association of the Euro Area with a sharp bias correction effect suggests that improvements in transparency, financial infrastructure combined with decreased transaction costs, might be instrumental in solving home bias. At the same time, the de facto abolition of the currency matching rule at the time of the introduction of the euro may further explain why the home bias has decreased more rapidly in the Euro Area. The phenomenon of home bias lies on the border between the rational sphere of information asymmetries and the behavioral realm of familiarity and perceptions. We expect that the Euro Area provides the best environment for conveying information and also for evening out the differences of (subjective) perceptions between foreign and domestic investors that are fundamental to home bias behavior.

In line with the hypothesis that higher transparency erodes home bias, we note that the elasticity of home bias with respect to international exposure indicators is consistently negative. However, the effect has little economic impact even when statistically significant. 
The additional control variables allow us to make several inferences about the possible drivers of home bias. First, we do not find support for the hypothesis that idiosyncratic risk plays a significant role as as a driver of international diversification. Second, we note that there is a positive relationship between the (change in) home bias and the relative importance of stock market in the economy. The elasticity coefficient is small in size even though predominantly significant or marginally insignificant. However, it suggests that domestic investors are more reluctant to leave a thriving market than foreign investors are eager to enter. Third, we observe the opposite effect with respect to financial structure. A higher share of bank assets, interpreted as a sign of lower financial diversification might at the same time raise the attractiveness of foreign markets and provide a reliable channel of information to local investors.

Furthermore, we estimate the same set of specifications with two other measures of home bias as independent variables, the volatility corrected 'data based' and the Bayesian home bias. Tables 5 and 6 report the results for these tests. Though paying a price in terms of instability, the alternative home bias series follow the same pattern. We find evidence of a negative trend and $\beta$-convergence as well as a strong and highly significant bias correction effect corresponding to the Euro Area. Similar to the I-CAPM home bias, we find for 'data based' and Bayesian home bias a significant added value of explanatory variables related to the financial diversification (growth of bank assets as a proportion of GDP) and international exposure indicators (foreign trade openness and foreign direct investments). However, in economic terms the effects are small, which presents them as channels affecting home bias but suggests the eventual solution of the puzzle may come from more intense forms of financial integration.

Overall our results substantiate the fact that home bias is consistently decreasing over time and more intensely in the Euro Area, over and above controls related to the development and structure of the stock market or a simple time trend.

\section{Concluding Remarks}

We investigate home bias behavior in a group of 25 countries and we observe its response to two challenges. The first challenge is methodological. We apply alternative measures of home bias that depart from the standard I-CAPM framework, allowing for certain degrees of mistrust in the model and also correcting for uncertainty about the sample estimates of expected returns. These alternative measures achieve two goals. First, they show that for many countries, home bias becomes significantly lower when these concerns are taken into account and the I-CAPM framework is not always an appropriate investment benchmark. Second, these measures offer a more comprehensive view of the phenomenon and support our conclusion that as globalization and regional integration proceed, investors take ad- 
vantage of the global market and their home bias is gradually eroding. The second challenge involves the effects of market integration. We find compelling evidence that integration, and especially its most intense form in the Euro Area relates significantly to the decrease of home bias. 


\section{Appendix A The Bayesian Framework}

This appendix outlines the steps of deriving the moments of the predictive distribution of excess returns, $r_{t+1}$, conditional on the set of sample data, $\Phi$ in terms of the prior and the likelihood function.

\section{The Prior}

The way in which the prior distribution incorporates the information given by the estimated intercept reflects the degree of belief in the model. Complete belief in the model assumes that the eventual nonzero intercepts are merely a result of sampling or estimation error and ignores them when computing the expectations of excess returns (the fitted value of the dependent variable) while complete disbelief in the model uses the sample mean as the estimate of expected returns. As our main interest lies in the intercept it sufficient to construct a prior which is informative only with respect to $\alpha$ and diffuse (highly volatile, non-informative) for the other parameters. Pástor (2000) chose a normal inverted Wishart prior for the intercept:

$$
\alpha \mid \Sigma \sim N\left(0, \sigma_{\alpha}^{2}\left(\frac{1}{s^{2}}\right)\right),
$$

with $\Sigma$ following a inverted Wishart distribution: $\Sigma^{-1} \sim W\left(H^{-1}, v\right)$, with $H^{-1}$ the parameter matrix of the Wishart distribution and $v$, the degrees of freedom. The expectation of the inverted Wishart distribution is given by $E(\Sigma)=\frac{H}{(v-N-1)}$, where $N$ is the number of asset returns in our time series. We can rewrite the expectation for the prior residual covariance matrix, as $E(\Sigma)=s^{2} I_{N}$, for $H=s^{2}(v-N-1)$ The prior involves a diagonal and homoskedastic covariance matrix for the residuals, which is set to be non-informative, by choosing $v=15$, the equivalent of the sample of 15 observations. The prior of homoskedasticity can easily be reversed under the pressure of data that enters the computation of the posterior density. At this point, taking expectation of the conditional prior distribution of $\alpha$, leads to an unconditional distribution in the from:

$$
\alpha \sim N\left(0, \sigma_{\alpha}^{2} I_{N}\right)
$$

where $\sigma_{\alpha}^{2}$ incorporates the degree of disbelief in the model. Based on the interpretation that the intercepts different than zero reflect omitted sources of risk from the model, the size of this mispricing is directly linked to the size of the residual covariance matrix. If the variance of the intercepts has been large, the model is consequently less trusted. The asset pricing model is linear in the benchmark risk factor, the world returns under the I-CAPM ${ }^{9}: R_{t}=\alpha+\beta F_{t}+\varepsilon_{t}$, assuming $E\left(\varepsilon_{t}\right)=0, E\left(\varepsilon_{t} \varepsilon_{t}^{\prime}\right)=\Sigma$, $E\left(F_{t}\right)=\mu_{t}, E\left[\left(F_{t}-\mu_{t}\right)\left(F_{t}-\mu_{t}\right)^{\prime}\right]=\Omega_{F}, \operatorname{cov}\left(F_{t}, \varepsilon_{i, t}\right)=0, \forall i=1, N$. The prior joint distribution is:

$$
p(\theta)=p(\alpha \mid \Sigma) p(\Sigma) p(\beta) p\left(\mu_{F}\right) p\left(\Omega_{F}\right),
$$

\footnotetext{
${ }^{9}$ Pástor (2000) derives the results for the general case of $N$ assets and $K$ benchmarks. In the case of International CAPM, the only benchmark is given by the world returns. Notation follows closely Asgharian and Hansson (2005).
} 
where only the priors on the last three distributions are diffuse as derived by Pástor and Stambaugh (2000):

$$
\begin{gathered}
p(\alpha \mid \Sigma) \propto|\Sigma|^{-\frac{1}{2}} \exp \left\{-\frac{1}{2} \alpha^{\prime}\left(\frac{\sigma_{\alpha}^{2}}{s^{2}} \Sigma\right)^{-1} \alpha\right\} \\
p(\Sigma) \propto|\Sigma|^{-\frac{(v+N+1)}{2}} \exp \left\{-\frac{1}{2} \operatorname{tr} H \Sigma^{-1}\right\} \\
p(\beta) \propto 1 \\
p\left(\mu_{F}\right) \propto 1 \\
p\left(\Omega_{F}\right)=\Omega_{F}^{-1}
\end{gathered}
$$

\section{The Likelihood}

In the linear model for asset returns, the disturbances are assumed uncorrelated and homoskedastic. The benchmark returns are assumed i.i.d., normal, independent over time and independent of the error terms. Under these independence assumptions, the likelihood function can be written as a product of two normal likelihood functions, for the returns on the assets and respectively for the returns on the benchmark factor:

$$
p(\Phi \mid \theta)=p(R \mid \theta, F) p(F \mid \theta) .
$$

The product terms are further expanded using computational results of Pástor and Stambaugh (2000) into:

$$
\begin{gathered}
p(R \mid \theta, F) \propto|\Sigma|^{-\frac{T}{2}} \exp \left(-\frac{T}{2} \operatorname{tr} \hat{\Sigma} \Sigma^{-1}-\frac{1}{2}(b-\hat{b})\left(\Sigma^{-1} \otimes F^{\prime} F\right)(b-\hat{b})\right), \\
p(F \mid \theta) \propto\left|\Omega_{F}\right|^{-\frac{T}{2}} \exp \left(-\frac{T}{2} \operatorname{tr} \hat{\Omega}_{F} \Omega_{F}^{-1}-\frac{1}{2}\left(\mu_{F}-\hat{\mu}_{F}\right)\left(\mu_{F}-\hat{\mu}_{F}\right)^{\prime} \Omega_{F}^{-1}\right),
\end{gathered}
$$

where $b=\operatorname{vec}(B)^{10}$ and $B=\left(\begin{array}{ll}\alpha & \beta\end{array}\right)^{\prime}$.

The Posterior Density

We return to the key relation of Bayesian analysis, that defines the posterior distribution via proportionality with the product of prior density and likelihood functions. Pástor and Stambaugh (2000) combine the results for the priors with the ones for the likelihood functions separately for the regression parameters and for the benchmark returns.

The posterior means of the model parameters result from:

$$
b \equiv E(b \mid \Phi)=\left(I_{N} \otimes P^{-1} X^{\prime} X\right) \hat{b},
$$

where $\hat{b}$ the vector of OLS estimates of the model on the dataset, $X=\left(\iota_{T} F\right), P=S+X^{\prime} X, D_{[2 \times 2]}$ is a matrix with the first element $d_{(1,1)}=\frac{s^{2}}{\sigma_{\alpha}^{2}}$ and the rest of the elements $d_{(m, n)}=0$, with $m, n \neq 1$.

\footnotetext{
${ }^{10}$ The transformation $v e c$ applied to a matrix, stacks its columns resulting into a vector.
} 
The posterior variance of the model parameters is given by:

$$
\operatorname{var}(b \mid \Phi)=\tilde{\Sigma} \otimes P^{-1},
$$

where $\tilde{\Sigma}=E(\Sigma \mid \Phi)=\frac{\left(H+T \hat{\Sigma}+\hat{B}^{\prime} Q \hat{B}\right)}{T-v-N-K-1}, Q=X^{\prime}\left(I_{T}-X P^{-1} X^{\prime}\right) X$ and $\hat{\Sigma}$ and $\hat{B}$ result from estimating the model on the available sample.

Finally, the predictive means and variance of asset returns are defined using the posterior moments.

The predictive means can be computed as:

$$
\mu^{*} \equiv E\left[R_{T+1} \mid \Phi\right]=\tilde{\mu}=\tilde{\alpha}+\tilde{\beta} \tilde{\mu}_{F},
$$

where $\tilde{\mu}, \tilde{\alpha}, \tilde{\beta}, \tilde{\mu}_{F}$ are posterior means and parameters.

The predictive variance-covariance matrix of asset returns is given by:

$$
\operatorname{cov}\left(R_{i, T+1} R_{j, T+1} \mid \Phi\right) \equiv \tilde{\beta}_{i}^{\prime} \Omega_{F}^{*} \tilde{\beta}_{j}+\operatorname{tr}\left[\Omega \operatorname{cov}\left(\beta_{i}, \beta_{j} \mid \Phi\right)\right]+\tilde{\sigma}_{i, j}+\left[\begin{array}{cc}
1 & \tilde{\mu}_{F}^{\prime}
\end{array}\right] \operatorname{cov}\left(b_{i}, b_{j}^{\prime} \mid \Phi\right)\left[\begin{array}{ll}
1 & \tilde{\mu}_{F}^{\prime}
\end{array}\right]^{\prime},
$$

where $\tilde{\sigma}_{i, j}$ is the respective $(i, j)$ element of the posterior variance covariance matrix, $\tilde{\Sigma}$ and $\Omega_{F}^{*}$ is the predictive covariance matrix factor employed by the model explaining the returns: $\Omega_{F}^{*}=\tilde{\Omega}_{F}+$ $\operatorname{var}\left(\mu_{F} \mid \Phi\right)$, where $\tilde{\Omega}_{F}=\frac{T \hat{\Omega}_{F}}{T-3}, \operatorname{var}\left(\mu_{F} \mid \Phi\right)=\frac{\hat{\Omega}_{F}}{T-3}$.

The analytical result for the predictive variance-covariance matrix for the asset returns is:

$$
\operatorname{cov}(R, F \mid \Phi)=\tilde{\beta} \tilde{\Omega}_{F}+\tilde{\beta} \operatorname{var}\left(\mu_{F} \mid \Phi\right) .
$$

\section{Appendix B The Multi-Prior Framework}

Garlappi, Uppal, and Wang (2004) prove that the Multi-Prior optimization problem in the case when uncertainty about the estimation of expected returns is expressed jointly for all assets, is equivalent to the maximization problem:

$$
\max _{\omega} \omega^{\prime} \mu-\frac{\gamma}{2} \omega^{\prime} \Sigma \omega-\sqrt{\varepsilon} \omega^{\prime} \Sigma \omega
$$

subject to

$$
\omega^{\prime} \iota=1
$$

where

$$
\varepsilon=\epsilon \frac{(T-1) N}{T(T-N)} .
$$

Without imposing short sales constrains, the problem can be solved analytically and the optimal weights are given by:

$$
\omega^{*}=\frac{\sigma_{P}^{*}}{\sqrt{\varepsilon}+\gamma \sigma_{P}^{*}} \Sigma^{-1}\left(\hat{\mu}-\frac{1}{A}\left(B-\frac{\sqrt{\varepsilon}+\gamma \sigma_{P}^{*}}{\sigma_{P}^{*}}\right) \iota\right)
$$


where $\sigma_{P}^{*}$ is the variance of the optimal portfolio and the (unique) positive real solution to the polynomial equation:

$$
A \gamma^{2} \sigma_{P}^{4}+2 A \gamma \sigma_{P}^{3}+\left(A \varepsilon-A C+B^{2}-\gamma^{2}\right) \sigma_{P}^{2}-2 \gamma \sqrt{\varepsilon} \sigma_{P}-\varepsilon=0,
$$

and $A=\iota^{\prime} \Sigma^{-1} \iota, B=\hat{\mu}^{\prime} \Sigma^{-1} \iota$ and $C=\hat{\mu}^{\prime} \Sigma^{-1} \hat{\mu}$.

\section{References}

Adam, Klaus, Tullio Jappelli, Annamaria Menichini, Mario Padula, and Marco Pagano, 2002, Analyse, compare and apply alternative indicators and monitoring methodologies to measure the evolution of capital market integration in the european union, CSEF.

Adler, Michael, and Bernard Dumas, 1983, International portfolio choice and corporation finance: A synthesis., Journal of Finance 38, 925-984.

Ahearne, Alan G., William L. Griever, and Francis E. Warnock, 2004, Information costs and home bias: An analysis of u.s. holdings of foreign equities, Journal of International Economics 62, 313-336.

Asgharian, Hossein, and Björn Hansson, 2005, Home bias among european investors within a bayesian framework, Journal of International Financial Markets, Institutions and Money, forthcoming.

Baele, Lieven, 2005, Volatility spillover effects in european equity markets, Journal of Financial and Quantitative Analysis 40, 373-401.

—_ Annalisa Ferrando, Peter Hördahl, Elizaveta Krylova, and Cyril Monnet, 2004, Measuring european financial integration, Oxford Review of Economic Policy 20, 509-530.

Baele, Lieven, and Koen Inghelbrecht, 2006, Structural versus temporary drivers of country and industry risk, Working Paper.

Beck, Thorsten, Asli Demirgüç-Kunt, and Levine Ross, 2000, A new database on financial development and structure, World Bank Economic Review 14, 597-605.

Bekaert, Geert, and Campbell R. Harvey, 1995, Time-varying world integration, Journal of Finance 50, $403-444$.

— , 1997, Emerging equity market volatility, Journal of Financial Economics 43, 29-77.

— 2000, Foreign speculators and emerging equity markets, Journal of Finance 55, 565-613.

Bekaert, Geert, Robert J. Hodrick, and Xiaoyan Zhang, 2005, International stock returns comovements, Working Paper. 
Black, Fisher, 1974, International capital market equilibrium with investment barriers, Journal of Financial Economics 1, 337-352.

Brennan, Michael J., and H. Henry Cao, 1997, International portfolio investment flows, Journal of Finance 52, 1851-1880.

Britten-Jones, Mark, 1994, The sampling error in estimates of mean-variance efficient portfolio weights, Journal of Finance 54, 655-671.

Chen, Nai-Fu, and Feng Zhang, 1997, Correlations, trades and stock returns of the pacific-basin markets, Pacific-Basin Finance Journal 7, 559-577.

Cooper, Ian, and Evi Kaplanis, 1994, Home bias in equity portfolios, inflation hedging, and international capital market equilibrium, Review of Financial Studies 7, 45-60.

Coval, Joshua D., and Tobias J. Moskowitz, 1999, Home bias at home: Local equity preference in domestic portfolios, Journal of Finance 54, 2045-2073.

De Roon, Frans A., and Th. E. Nijman, 2001, Testing for mean-variance spanning: A survey, Journal of Empirical Finance 8, 111-156.

De Santis, Roberto A., and Bruno Gérard, 2006, Financial integration, international portfolio choice and the European Monetary Union, ECB Working Paper 626.

Eiling, Esther, Bruno Gerard, and Frans De Roon, 2004, Asset allocation in the Euro-Zone: Industry or country based?, Working Paper.

Errunza, Vihang, and Etienne Losq, 1981, International asset pricing under mild segmentation: Theory and test, Journal of Finance 40, 105-124.

Fidora, Michael, Marcel Fratzscher, and Christian Thimann, 2006, Home bias in global bond and equity markets: The role of real exchange rate volatility, Working Paper.

Fratzcher, Marcel, 2002, Financial market integration in Europe: on the effects of EMU on stock markets, International Journal of Finance and Economics 7, 165-193.

French, Kenneth R., and James M. Poterba, 1991, Investor diversification and international equity markets, American Economic Review 81, 222-226.

Garlappi, Lorenzo, Raman Uppal, and Tan Wang, 2004, Portfolio selection with parameter and model uncertainty: A multi-prior approach, Working Paper. 
Gehrig, Thomas, 1993, An information based explanation of the domestic bias in international equity investment, Scandinavian Journal of Economics 95, 97-109.

Glassman, Debra A., and Leigh A Riddick, 2001, What causes home asset bias and how should it be measured?, Journal of Empirical Finance 8, 35-54.

Goergen, Marc, Marina Martynova, and Luc Renneboog, 2005, Corporate governance convergence, evidence from takeover regulation reforms, Oxford Review of Economic Policy 21, 243-268.

Griever, William L., Gary A. Lee, and Francis E. Warnock, 2001, The U.S. system for measuring crossborder investment in securities: A primer with a discussion of recent developments, Federal Reserve Bulletin.

Griffin, John M., and G. Andrew Karolyi, 1998, Another look at the role of the industrial structure of markets for international diversification strategies, Journal of Financial Economics 50, 351-373.

Grinblatt, Mark, and Matti Keloharju, 2000, The investment behavior, and performance of various investor types: A study of finland's unique data set, Journal of Financial Economics 55, 43-67.

Heston, Steven L., and K. Geert Rouwenhorst, 1994, Does industrial structure explain the benefits of international diversification?, Journal of Financial Economics 36, 3-27.

Huberman, Gur, 2001, Familiarity breeds investment, Review of Financial Studies 14, 659-680.

Jenske, Karsten, 2001, Equity home bias - can information cost explain the puzzle?, Federal Reserve Bank of Atlanta Economic Review.

Kho, Bong-Chan, René Stulz, and Francis M. Warnock, 2006, Financial globalization, governance, and the evolution of the home bias, Working Paper.

Koop, Gary, 2003, Bayesian Econometrics (John Wiley and Sons Ltd).

Lane, Philip R., and Gian Maria Milesi - Ferretti, 2003, Centre of economic policy research, International Financial Integration.

Levine, Ross, and Sara Zervos, 1996, Stock market development and long-run growth, World Bank Policy Research Working Paper 1582.

Lewis, Karen K., 1999, Trying to explain home bias in equities and consumption, Journal of Economic Literature 37, 571-608.

Li, Kai, 2002, Confidence in the familiar: An international perspective, Journal of Financial and Quantitative Analysis, forthcoming. 
Lintner, John, 1965, The valuation of risky assets and the selection of risky investments in stock portfolios and capital budgets, Review of Economics and Statistics 47, 13-37.

Longin, François, and Bruno Solnik, 1995, Is the correlation in international equity returns constant: 1960-1990?, Journal of International Money and Finance 14, 3-26.

Mann, Catherine L., and Ellen E. Meade, 2002, Home bias, transaction costs, and prospects for the euro: A more detailed analysis, IIE Working Paper Series.

Markowitz, Harry M., 1952, Portfolio selection, Journal of Finance 7, 77-91.

Merton, Robert C., 1980, On estimating the expected return on the market, Journal of Financial Economics 8, 323-361.

Pástor, Luboš, 2000, Portfolio selection and asset pricing models, Journal of Finance 55, 179-223.

— , and Robert F. Stambaugh, 2000, Comparing asset pricing models: An investment perspective, Journal of Financial Economics 56, 335-381.

Sharpe, William, 1963, A simplified model for portfolio analysis, Management Science 9, 277-293.

Stockman, Alan C., and Harris Dellas, 1989, International portfolio nondiversification and exchange rate variability, Journal of International Economics 26, 271-289.

Stulz, René, 1981, On the effects of barriers to international investment, Journal of Finance 36, 923-934.

Tesar, Linda L., and Ingrid Werner, 1995, Home bias and high turnover, Journal of International Money and Finance 14, 467-492.

Warnock, Francis E., 2001, Home bias and high turnover reconsidered, Working Paper. 
Table 1: Descriptive statistics - International Investment Position

This table presents some descriptive statistics (number of observations, mean of the full sample (Mean) and means of the first and second halves of the sample, (Mean1 and Mean2) ) for the main data needed to compute home bias: portfolio holdings of foreign assets and foreign liabilities (in million USD) reported in the International Investment Position of the Balance of Payments and recorded in IMF International Financial Services Database, as well as relative market share in percentages (computed as the ratio of the domestic market capitalization to the MSCI World Market Capitalization). All series are recorded with annual frequency.

\begin{tabular}{|c|c|c|c|c|c|c|c|c|c|c|c|c|}
\hline \multirow[t]{2}{*}{ Country } & \multicolumn{4}{|c|}{$\begin{array}{l}\text { Foreign Assets } \\
\text { (million USD) }\end{array}$} & \multicolumn{4}{|c|}{$\begin{array}{l}\text { Foreign Liabilities } \\
\quad(\text { million USD) }\end{array}$} & \multicolumn{4}{|c|}{$\begin{array}{c}\text { Relative Market } \\
\text { Shares (\%) }\end{array}$} \\
\hline & \# & Mean & Mean1 & Mean2 & $\#$ & Mean & Mean1 & Mean2 & \# & Mean & Mean1 & Mean2 \\
\hline Austria & 24 & 10267 & 1522 & 23450 & 24 & 6628 & 756 & 16206 & 32 & 0.11 & 0.05 & 0.16 \\
\hline Belgium & 23 & 53038 & 17438 & 91874 & 23 & 8355 & 2771 & 14447 & 32 & 0.55 & 0.49 & 0.62 \\
\hline Czech Rep & 6 & 30 & 484 & 2361 & 6 & 138 & 2549 & 4899 & 7 & 0.07 & 0.07 & 0.07 \\
\hline Denmark & 11 & 1254 & 9440 & 41699 & 11 & 3213 & 6001 & 22107 & 11 & 0.26 & 0.19 & 0.34 \\
\hline Finland & 24 & 5235 & 45 & 14825 & 18 & 50777 & 4116 & 108635 & 17 & 0.44 & 0.19 & 0.70 \\
\hline France & 15 & 116820 & 51334 & 223024 & 15 & 232100 & 91366 & 417806 & 32 & 2.51 & 1.51 & 3.63 \\
\hline Germany & 24 & 173700 & 27447 & 373783 & 24 & 125660 & 42031 & 240094 & 32 & 4.04 & 4.30 & 3.73 \\
\hline Greece & 6 & 1551 & 1269 & 3476 & 6 & 11512 & 11127 & 17650 & 30 & 0.24 & 0.21 & 0.26 \\
\hline Hungary & 7 & 209 & 103 & 489 & 7 & 3454 & 3045 & 5854 & 14 & 0.06 & 0.02 & 0.09 \\
\hline Iceland & 13 & 946 & 109 & 2388 & 9 & 37 & 16 & 519 & 8 & 0.03 & 0.01 & 0.04 \\
\hline Italy & 32 & 48164 & 2867 & 117044 & 18 & 22415 & 7200 & 48199 & 32 & 1.39 & 0.99 & 1.84 \\
\hline Netherlands & 22 & 98040 & 25866 & 205155 & 22 & 136290 & 43871 & 255755 & 32 & 1.98 & 1.79 & 2.19 \\
\hline Poland & 8 & 76 & 25 & 316 & 10 & 3619 & 2668 & 6767 & 14 & 0.08 & 0.03 & 0.13 \\
\hline Portugal & 8 & 7244 & 6124 & 10321 & 11 & 13991 & 8037 & 25491 & 28 & 0.12 & 0.05 & 0.19 \\
\hline Spain & 24 & 15706 & 742 & 30671 & 24 & 44111 & 7455 & 87431 & 18 & 1.23 & 1.04 & 1.46 \\
\hline Switzerland & 21 & 117170 & 40034 & 214524 & 21 & 169330 & 69452 & 295332 & 24 & 2.61 & 2.49 & 2.73 \\
\hline UK & 24 & 292620 & 121646 & 526320 & 24 & 291360 & 57633 & 605335 & 32 & 8.11 & 7.29 & 9.02 \\
\hline Sweden & 21 & 31836 & 4539 & 69124 & 21 & 36957 & 6809 & 78412 & 23 & 0.67 & 0.38 & 0.96 \\
\hline Turkey & 8 & 23 & 5 & 72 & 8 & 6701 & 7113 & 8545 & 28 & 0.15 & 0.04 & 0.17 \\
\hline Australia & 18 & 38735 & 16329 & 61142 & 18 & 61867 & 27231 & 96503 & 32 & 1.34 & 1.21 & 1.48 \\
\hline Canada & 6 & 131240 & 115033 & 147447 & 6 & 60054 & 51527 & 68580 & 32 & 2.40 & 2.50 & 2.28 \\
\hline Hong Kong & 5 & 126190 & 92887 & 176140 & 5 & 115830 & 106733 & 129480 & 32 & 1.32 & 0.84 & 1.86 \\
\hline Japan & 10 & 229420 & 190930 & 267914 & 10 & 240890 & 72159 & 419317 & 32 & 23.57 & 27.28 & 19.35 \\
\hline N. Zealand & 14 & 4989 & 1141 & 8837 & 14 & 2885 & 920 & 5130 & 17 & 0.12 & 0.13 & 0.10 \\
\hline USA & 25 & 741070 & 110252 & 1424461 & 25 & 638190 & 177118 & 1137665 & 32 & 44.62 & 48.27 & 40.48 \\
\hline
\end{tabular}




\section{Table 2: Test of I-CAPM}

This table reports the results of the OLS regressions of weekly (excess) returns on domestic market indices on a constant and the (excess) returns on the World Market Index for 25 countries. As the length of time series varies across the countries, the date of the first observation included in the estimation is reported in the second column of the table. Values of the coefficients, their respective standard errors and $R^{2}$, as a measure of goodness of fit of the model are reported subsequently. Significance is denoted by *** (at $1 \%)$, ** (at $5 \%$ ) and * (at $10 \%)$.

\begin{tabular}{|c|c|c|c|c|c|c|}
\hline Country & 1st obs. & Alpha & Std. Err. & Beta & Std. Err. & $R^{2}(\%)$ \\
\hline Austria & 09/01/1975 & 0.03 & 0.05 & $0.35^{* * *}$ & 0.02 & 9 \\
\hline Belgium & 09/01/1975 & 0.05 & 0.04 & $0.53^{* * *}$ & 0.02 & 23 \\
\hline Czech Rep & $16 / 11 / 1995$ & 0.10 & 0.12 & $0.57^{* * *}$ & 0.06 & 11 \\
\hline Denmark & 09/01/1975 & $0.10^{*}$ & 0.05 & $0.42^{* * *}$ & 0.02 & 11 \\
\hline Finland & $22 / 03 / 1990$ & 0.13 & 0.12 & $1.09 * * *$ & 0.06 & 25 \\
\hline France & 09/01/1975 & 0.08 & 0.05 & $0.73^{* * *}$ & 0.02 & 26 \\
\hline Germany & 09/01/1975 & 0.00 & 0.04 & $0.65^{* * *}$ & 0.02 & 29 \\
\hline Greece & 09/12/1993 & $0.26^{*}$ & 0.14 & $0.70^{* * *}$ & 0.07 & 11 \\
\hline Hungary & $17 / 06 / 1993$ & 0.27 & 0.13 & $0.92^{* * *}$ & 0.07 & 18 \\
\hline Iceland & 05/01/1995 & $0.25^{* * *}$ & 0.06 & $0.08^{* * *}$ & 0.03 & 1 \\
\hline Italy & 09/01/1975 & 0.10 & 0.07 & $0.61^{* * *}$ & 0.03 & 13 \\
\hline Netherlands & 09/01/1975 & 0.04 & 0.04 & $0.69^{* * *}$ & 0.02 & 35 \\
\hline Poland & 07/03/1996 & 0.00 & 0.19 & $0.91^{* * *}$ & 0.10 & 12 \\
\hline Portugal & 09/12/1993 & 0.02 & 0.07 & $0.58^{* * *}$ & 0.03 & 24 \\
\hline Spain & 09/03/1989 & 0.08 & 0.07 & $0.84^{* * *}$ & 0.03 & 36 \\
\hline Switzerland & 09/01/1975 & 0.00 & 0.04 & $0.60^{* * *}$ & 0.02 & 31 \\
\hline UK & $11 / 01 / 1973$ & 0.08 & 0.05 & $0.76^{* * *}$ & 0.02 & 31 \\
\hline Sweden & $12 / 01 / 1984$ & 0.10 & 0.07 & $0.93^{* * *}$ & 0.04 & 30 \\
\hline Turkey & 11/01/1990 & $1.09^{* * *}$ & 0.23 & $0.85^{* * *}$ & 0.12 & 5 \\
\hline Australia & 09/01/1975 & 0.08 & 0.05 & $0.58^{* * *}$ & 0.02 & 19 \\
\hline Canada & 09/01/1975 & 0.02 & 0.03 & $0.72^{* * *}$ & 0.01 & 45 \\
\hline Hong Kong & 09/01/1975 & 0.13 & 0.09 & $0.92^{* * *}$ & 0.04 & 17 \\
\hline Japan & 09/01/1975 & -0.06 & 0.04 & $0.76^{* * *}$ & 0.02 & 37 \\
\hline New Zealand & 11/01/1990 & 0.07 & 0.07 & $0.46^{* * *}$ & 0.03 & 14 \\
\hline USA & 09/01/1975 & 0.01 & 0.02 & $0.99 * * *$ & 0.01 & 71 \\
\hline
\end{tabular}


Table 3: Descriptive Statistics - Home Bias Measures

This table presents some descriptive statistics (mean, median and standard deviation) of the measure of home bias: (1) home bias computed in I-CAPM framework, (2) data based home bias, (3) home bias computed in a Bayesian framework $\left(\sigma_{\alpha}^{2}=0.05\right)$, (4) home bias computed by applying the Multi-Prior correction to the data based approach, (5) home bias computed by applying the Multi-Prior correction to the Bayesian approach $\left(\left(\sigma_{\alpha}^{2}=0.05\right)\right.$. All data comprises end-of-year values.

\begin{tabular}{|c|c|c|c|c|c|c|c|c|c|c|c|c|c|c|c|}
\hline \multirow[t]{2}{*}{ Country } & \multicolumn{3}{|c|}{$\begin{array}{c}-1- \\
\text { I-CAPM }\end{array}$} & \multicolumn{3}{|c|}{$\begin{array}{c}-2- \\
\text { DATA }\end{array}$} & \multicolumn{3}{|c|}{$\begin{array}{c}\text {-3- } \\
\text { BAYESIAN } \\
\sigma_{\alpha}^{2}=0.05\end{array}$} & \multicolumn{3}{|c|}{$\begin{array}{c}-4- \\
\text { MPC } \\
\text { DATA }\end{array}$} & \multicolumn{3}{|c|}{$\begin{array}{c}-\mathbf{5 -} \\
\text { MPC BAYESIAN } \\
\sigma_{\alpha}^{2}=0.05\end{array}$} \\
\hline & Mean & Med & Std & Mean & Med & Std & Mean & Med & Std & Mean & Med & Std & Mean & Med & Std \\
\hline Austria & 0.58 & 0.61 & 0.20 & 0.24 & 0.50 & 0.70 & 0.24 & 0.50 & 0.70 & 0.08 & 0.40 & 0.77 & 0.07 & 0.40 & 0.78 \\
\hline Belgium & 0.55 & 0.54 & 0.06 & -0.03 & 0.20 & 0.60 & 0.00 & 0.23 & 0.59 & 0.23 & 0.24 & 0.12 & 0.24 & 0.26 & 0.32 \\
\hline Czech Rep & 0.88 & 0.90 & 0.08 & 0.88 & 0.86 & 0.06 & 0.88 & 0.89 & 0.07 & 0.87 & 0.88 & 0.08 & 0.87 & 0.89 & 0.08 \\
\hline Denmark & 0.69 & 0.71 & 0.09 & 0.37 & 0.46 & 0.22 & 0.47 & 0.54 & 0.18 & 0.47 & 0.52 & 0.17 & 0.51 & 0.56 & 0.15 \\
\hline Finland & 0.87 & 0.94 & 0.14 & 0.28 & 0.84 & 0.93 & 0.33 & 0.85 & 0.91 & 0.84 & 0.93 & 0.18 & 0.84 & 0.93 & 0.18 \\
\hline France & 0.77 & 0.78 & 0.03 & 0.42 & 0.50 & 0.22 & 0.49 & 0.56 & 0.17 & 0.62 & 0.63 & 0.08 & 0.63 & 0.65 & 0.07 \\
\hline Germany & 0.73 & 0.70 & 0.13 & 0.25 & 0.60 & 0.86 & 0.29 & 0.60 & 0.81 & 0.61 & 0.58 & 0.17 & 0.61 & 0.58 & 0.17 \\
\hline Greece & 0.98 & 0.98 & 0.01 & 0.07 & 0.65 & 1.01 & 0.66 & 0.94 & 0.75 & 0.95 & 0.97 & 0.03 & 0.96 & 0.97 & 0.02 \\
\hline Hungary & 0.98 & 0.98 & 0.02 & 0.69 & 0.96 & 0.70 & 0.70 & 0.96 & 0.71 & 0.97 & 0.97 & 0.01 & 0.97 & 0.97 & 0.01 \\
\hline Iceland & 0.74 & 0.74 & 0.06 & 0.06 & 0.05 & 0.41 & 0.11 & 0.11 & 0.40 & 0.24 & 0.17 & 0.26 & 0.27 & 0.20 & 0.25 \\
\hline Italy & 0.82 & 0.90 & 0.11 & 0.69 & 0.82 & 0.23 & 0.71 & 0.84 & 0.21 & 0.75 & 0.85 & 0.17 & 0.76 & 0.86 & 0.16 \\
\hline Netherlands & 0.60 & 0.63 & 0.08 & -0.09 & 0.02 & 0.58 & -0.03 & 0.11 & 0.56 & 0.21 & 0.25 & 0.20 & 0.24 & 0.28 & 0.19 \\
\hline Poland & 0.99 & 0.99 & 0.00 & 0.99 & 0.99 & 0.00 & 0.99 & 0.99 & 0.00 & 0.99 & 0.99 & 0.00 & 0.99 & 0.99 & 0.00 \\
\hline Portugal & 0.79 & 0.82 & 0.07 & 0.31 & 0.55 & 0.85 & 0.38 & 0.57 & 0.82 & 0.68 & 0.69 & 0.11 & 0.69 & 0.69 & 0.11 \\
\hline Spain & 0.91 & 0.96 & 0.10 & 0.25 & 0.79 & 0.94 & 0.47 & 0.88 & 0.79 & 0.85 & 0.95 & 0.16 & 0.87 & 0.95 & 0.14 \\
\hline Switzerland & 0.61 & 0.62 & 0.04 & 0.38 & 0.63 & 0.81 & 0.38 & 0.63 & 0.80 & 0.57 & 0.52 & 0.18 & 0.55 & 0.52 & 0.14 \\
\hline UK & 0.69 & 0.69 & 0.03 & -0.06 & 0.10 & 0.63 & 0.07 & 0.26 & 0.60 & 0.47 & 0.49 & 0.10 & 0.52 & 0.54 & 0.07 \\
\hline Sweden & 0.73 & 0.70 & 0.13 & 0.51 & 0.54 & 0.29 & 0.61 & 0.58 & 0.20 & 0.63 & 0.59 & 0.16 & 0.65 & 0.61 & 0.16 \\
\hline Turkey & 0.99 & 0.99 & 0.00 & 0.32 & 0.99 & 1.00 & 0.77 & 0.99 & 0.66 & 0.99 & 0.99 & 0.00 & 0.99 & 0.99 & 0.00 \\
\hline Australia & 0.83 & 0.83 & 0.02 & 0.69 & 0.71 & 0.10 & 0.72 & 0.74 & 0.08 & 0.75 & 0.76 & 0.05 & 0.76 & 0.77 & 0.04 \\
\hline Canada & 0.81 & 0.82 & 0.04 & 0.64 & 0.66 & 0.13 & 0.65 & 0.67 & 0.13 & 0.68 & 0.69 & 0.08 & 0.68 & 0.69 & 0.08 \\
\hline Hong Kong & 0.77 & 0.77 & 0.04 & 0.61 & 0.58 & 0.08 & 0.70 & 0.67 & 0.05 & 0.71 & 0.70 & 0.04 & 0.74 & 0.73 & 0.04 \\
\hline Japan & 0.90 & 0.90 & 0.02 & 0.94 & 0.95 & 0.00 & 0.94 & 0.94 & 0.00 & 0.91 & 0.91 & 0.01 & 0.91 & 0.91 & 0.01 \\
\hline N. Zealand & 0.83 & 0.86 & 0.15 & 0.50 & 0.81 & 0.60 & 0.69 & 0.83 & 0.36 & 0.74 & 0.83 & 0.25 & 0.75 & 0.83 & 0.23 \\
\hline USA & 0.82 & 0.83 & 0.09 & 0.45 & 0.76 & 0.64 & 0.46 & 0.77 & 0.64 & 0.79 & 0.79 & 0.16 & 0.79 & 0.79 & 0.16 \\
\hline Average & 0.80 & 0.81 & 0.07 & 0.42 & 0.62 & 0.49 & 0.51 & 0.67 & 0.48 & 0.68 & 0.69 & 0.19 & 0.67 & 0.70 & 0.14 \\
\hline
\end{tabular}




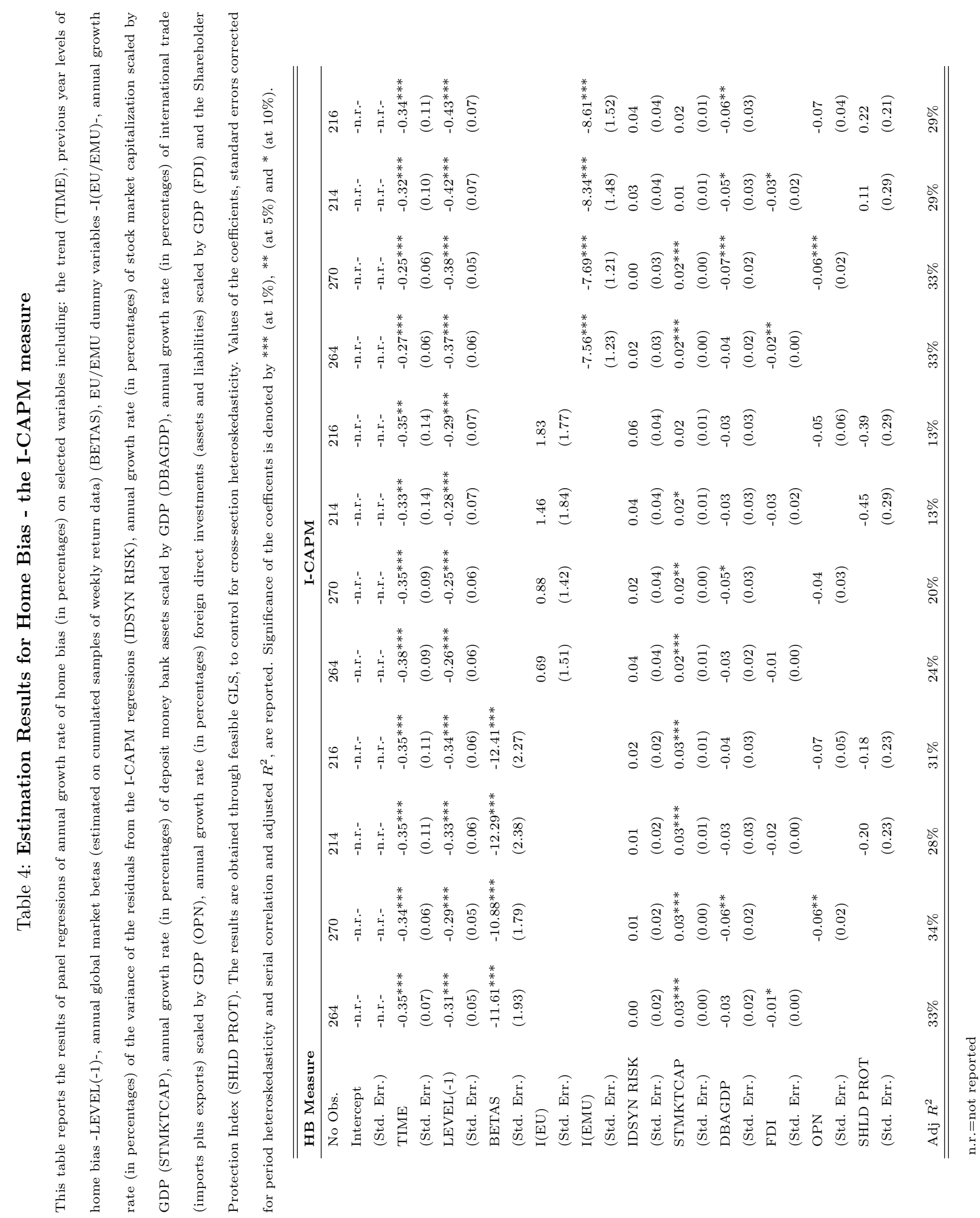




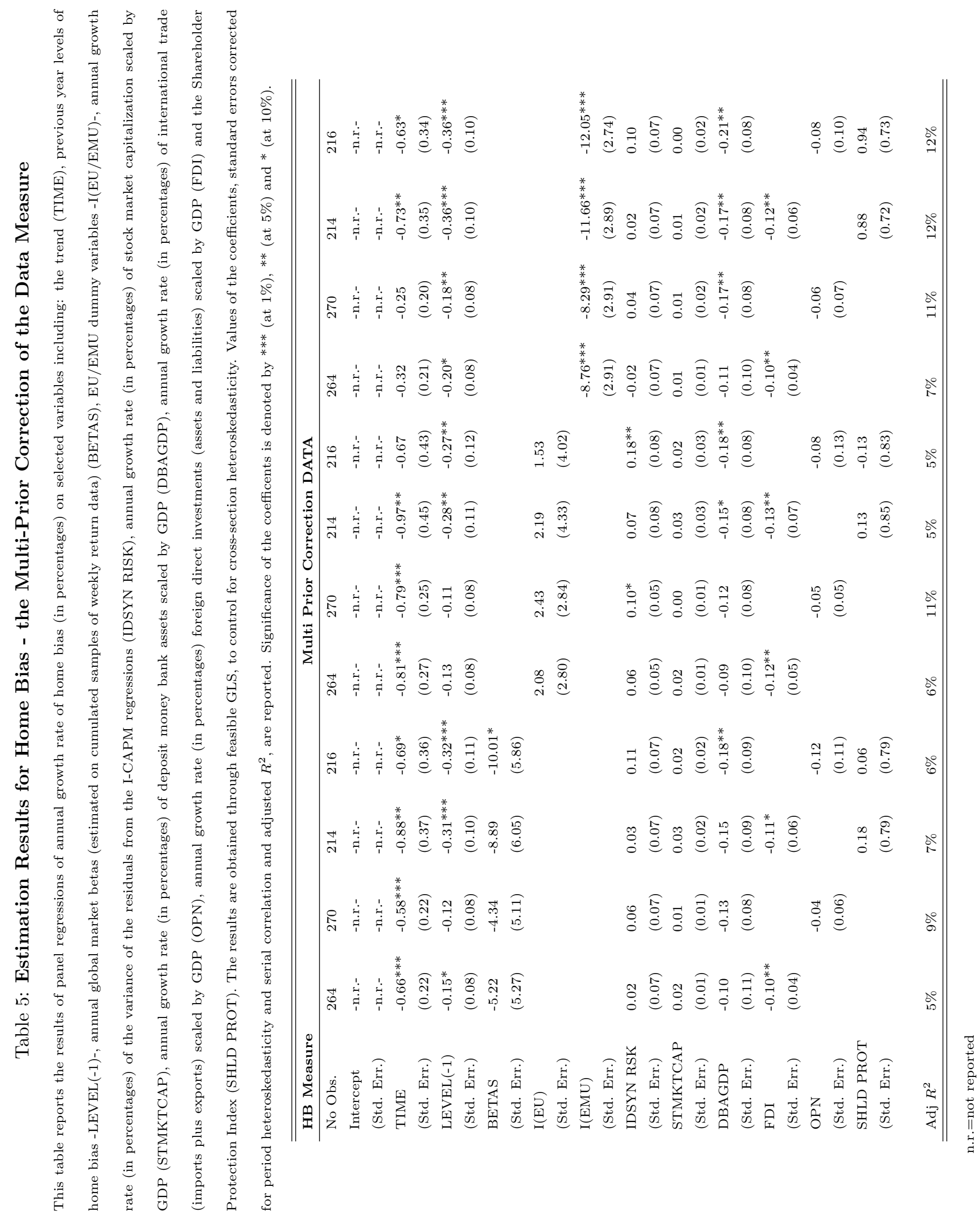




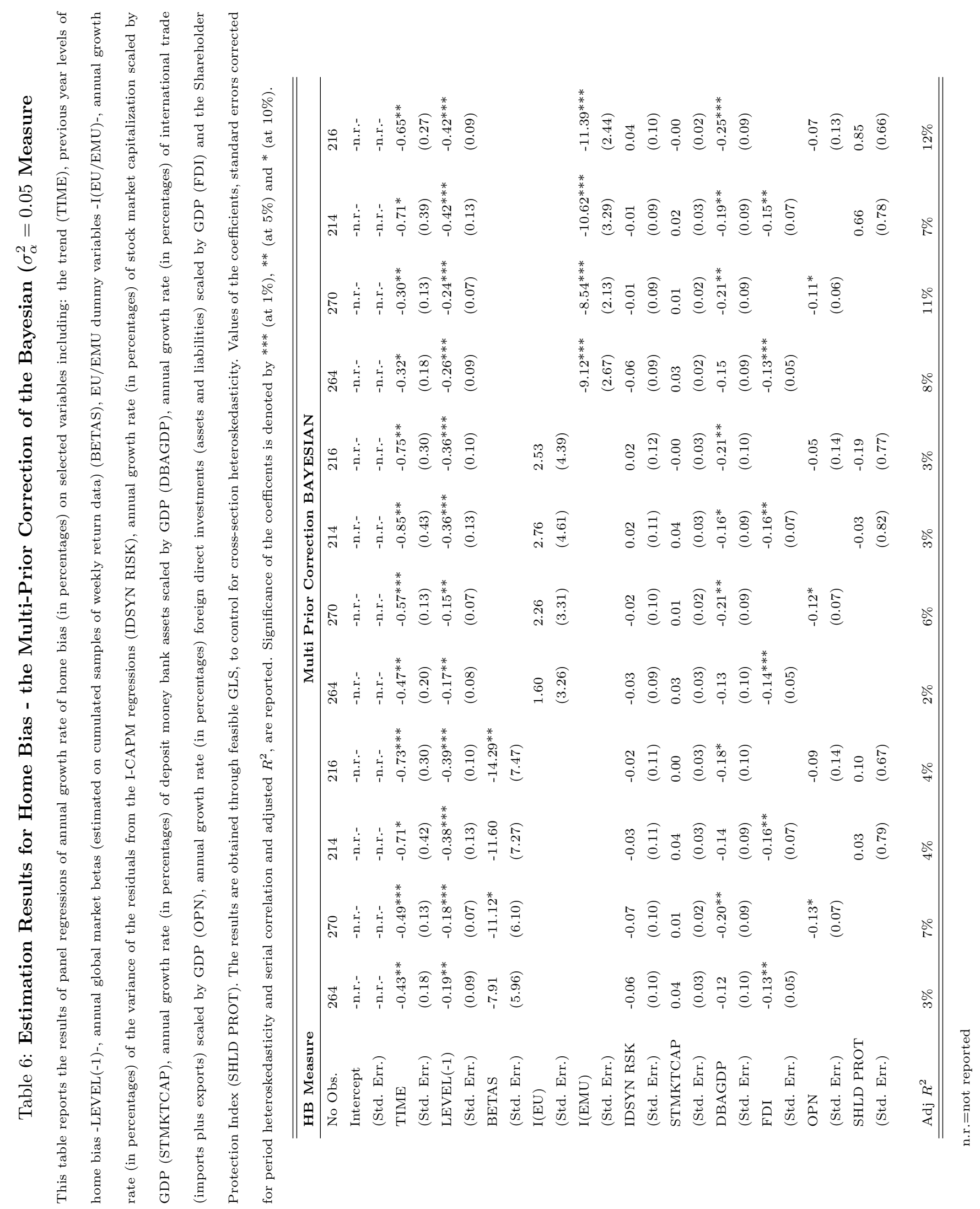


Figure 1: Home Bias (short sales allowed)
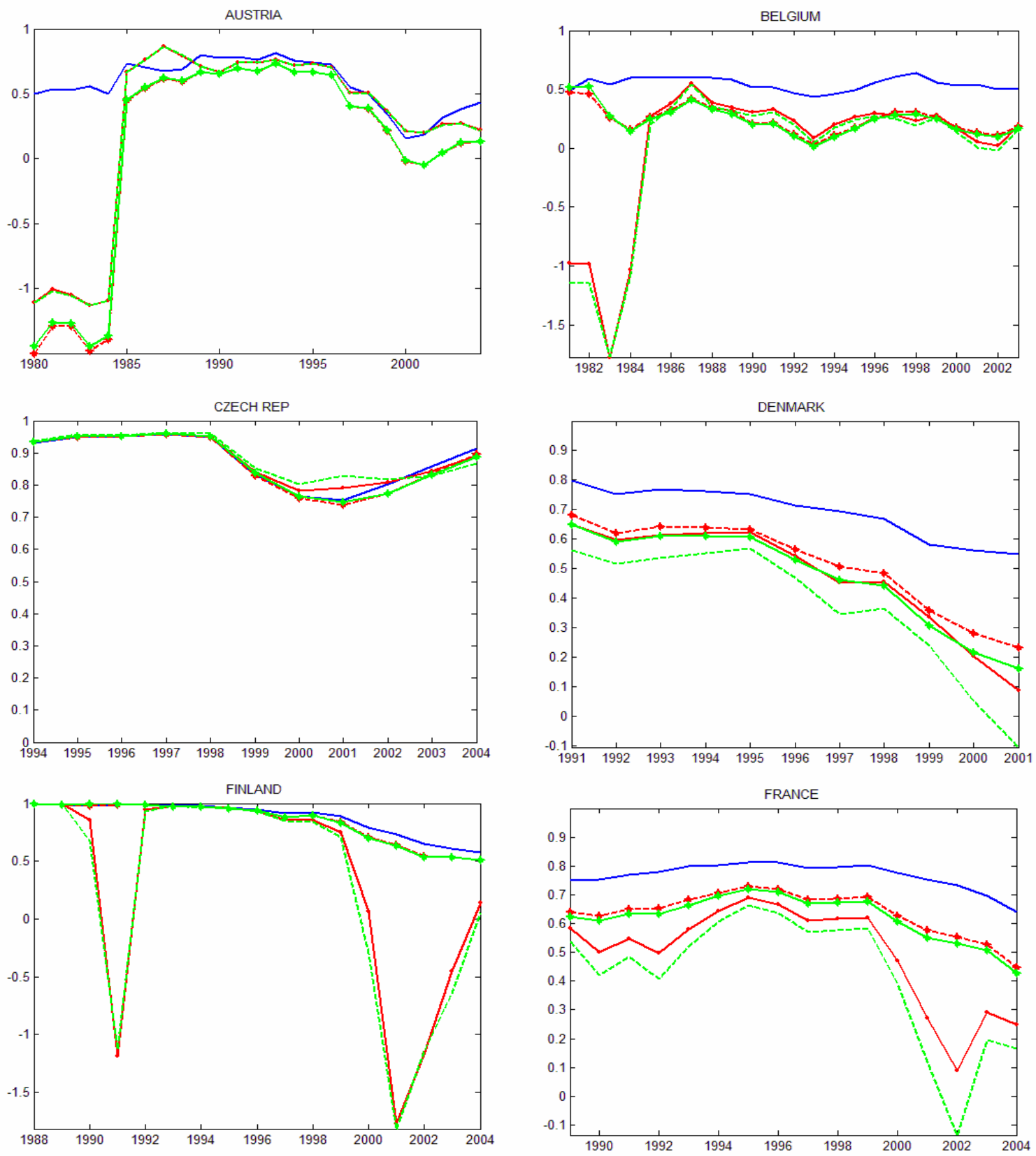

\section{Legend}

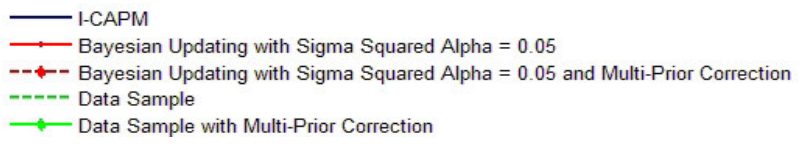


Figure 2: Home Bias (short sales allowed)
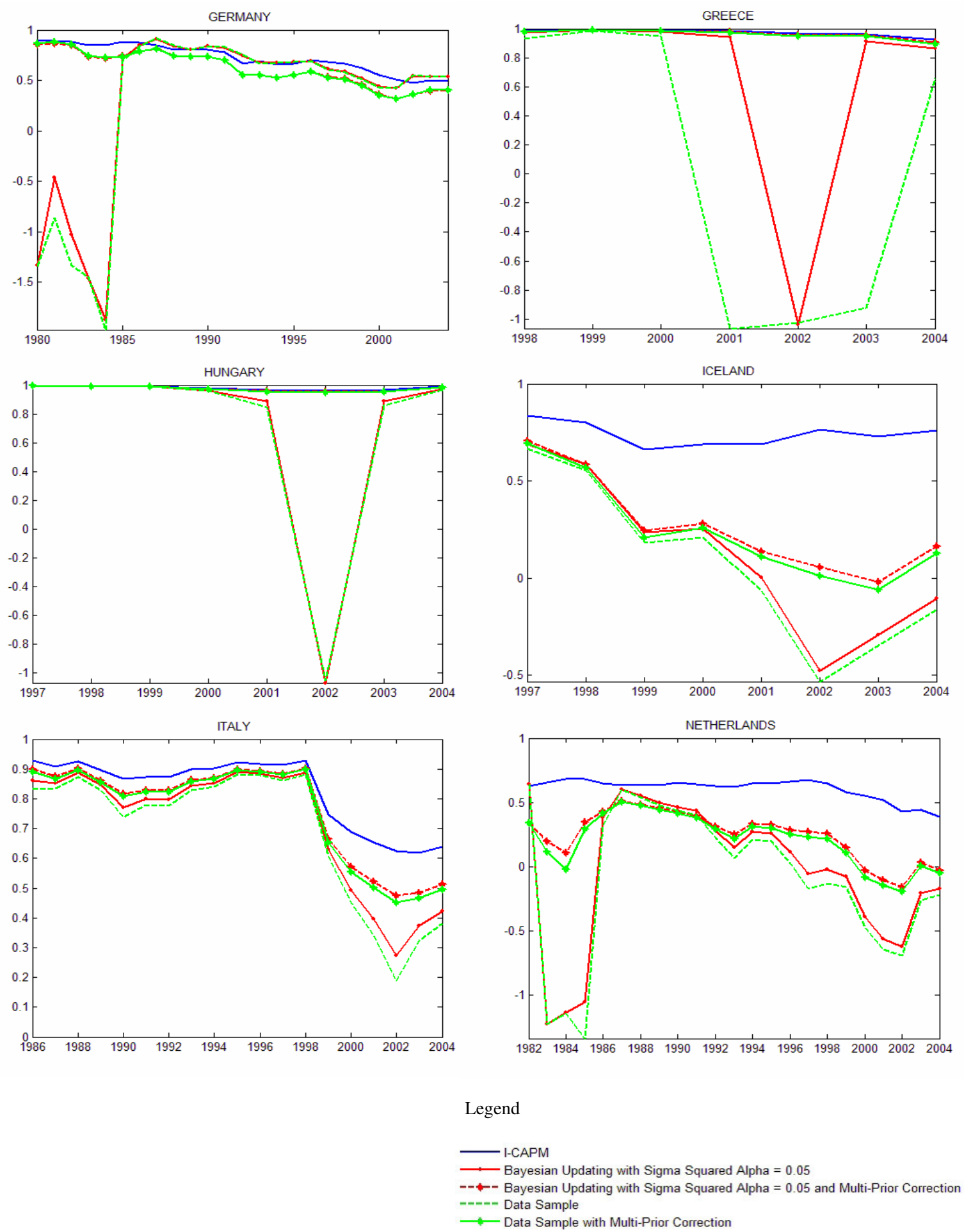
Figure 3: Home Bias (short sales allowed)
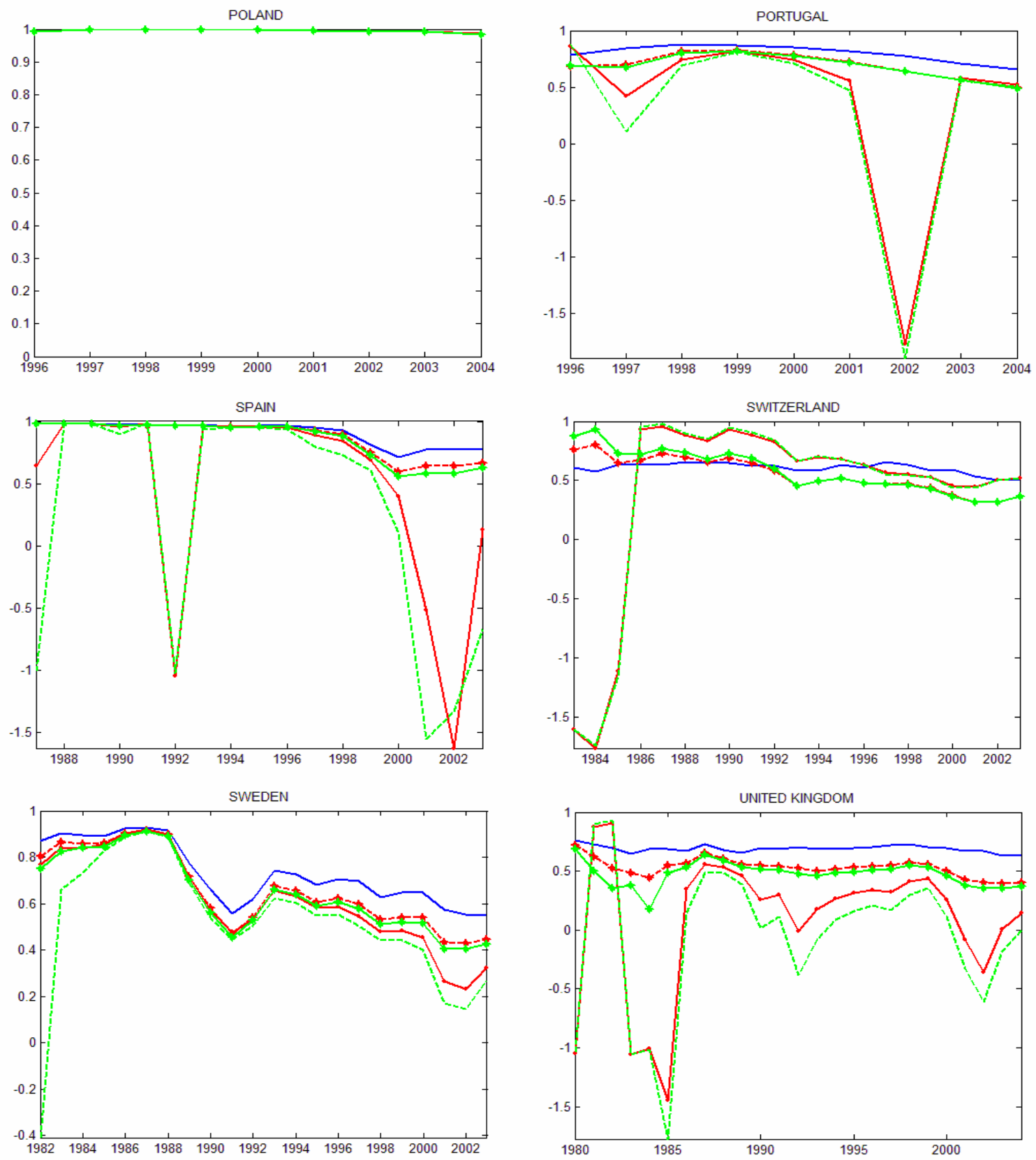

Legend

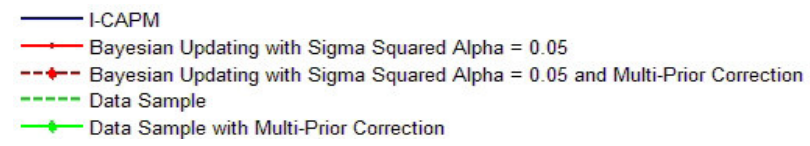


Figure 4: Home Bias (short sales allowed)
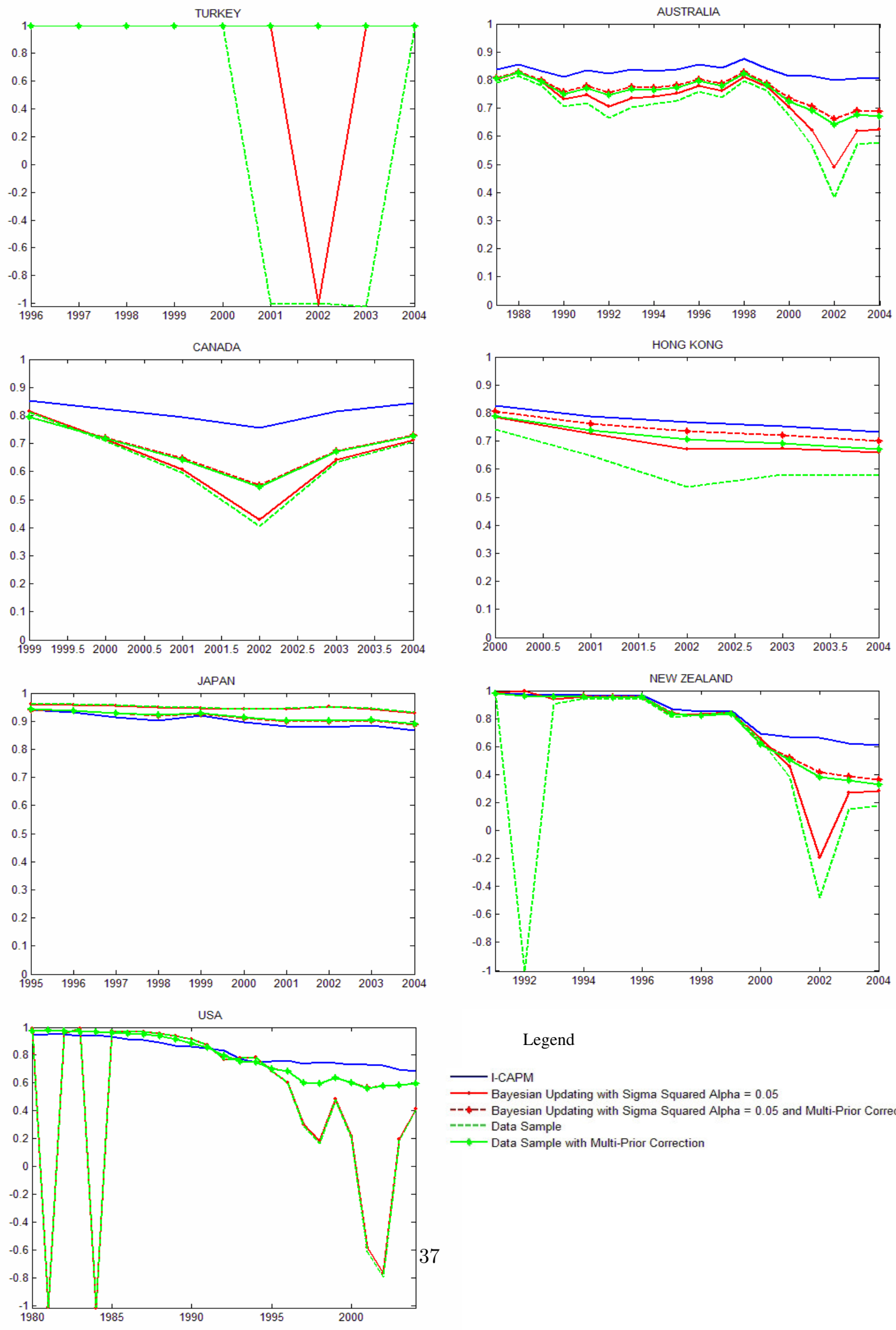

\section{Legend}

I-CAPM

- Bayesian Updating with Sigma Squared Alpha $=0.05$

-- -- Bayesian Updating with Sigma Squared Alpha $=0.05$ and Multi-Prior Correction ----- Data Sample

$\longrightarrow$ Data Sample with Multi-Prior Correction 